\title{
Current, wave, wind and interaction induced dynamic response of a 5MW spar-type offshore direct-drive wind turbine
}

Kan $\mathrm{Ye}^{*}$, Jinchen Ji

School of Mechanical and Mechatronic Systems, FEIT

University of Technology Sydney, Ultimo NSW 2007, Australia

Email: kan.ye@uts.edu.au, jin.ji@uts.edu.au 


\section{AUTHOR DECLARATION}

We wish to confirm that there are no known conflicts of interest associated with this publication and there has been no significant financial support for this work that could have influenced its outcome.

We confirm that the manuscript has been read and approved by all named authors and that are no other persons who satisfied the criteria for authorship but are not listed. We further confirm that the order of authors listed in the manuscript has been approved by all of us.

We confirm that we have given due consideration to the protection of intellectual property associated with this work and that there are no impediments to publication, including the timing of publication, with respect to intellectual property. In so doing we confirm that we have followed the regulations of our institutions concerning intellectual property.

We understand that the Corresponding Author is the sole contact for the Editorial process (including Editorial Manager and direct communications with the office). He/she is responsible for communicating with the other authors about progress, submissions of revisions and final approval of proofs. We confirm that we have provided a current, correct email address which is accessible by the Corresponding Author and which has been configured to accept email from kan.ye@uts.edu.au 


\begin{abstract}
This paper studies the dynamic response of a spar-type direct-drive wind turbine subjected to external and internal excitations. A free-free end model is developed for the wind turbine structure with a spar-type floating platform under deep sea condition. Firstly, the spar supported platform with tower structure is modelled as a rigid body while the nacelle is considered as a point mass attached on the top of the tower. Then the dynamic interaction between the drivetrain system and the tower is considered by incorporating the modelling of a direct-drive drivetrain system. The hydrodynamic and aerodynamic excitations applied include current, wave, and wind excitations as well as buoyant forces. The misalignments of the wind, wave and current are also considered to examine the induced response. With the help of the time history and FFT spectrum, the effects of both hydrodynamic and aerodynamic excitations along with the dynamic interaction between the drive-train system and tower structure on the dynamic behaviour of the spar-type floating platform are investigated under different sea conditions.
\end{abstract}

Keywords: offshore wind turbine, spar-type platform, dynamic response, wave, wind, interaction, misalignment 


\section{Introduction}

Land-based wind power has been the world's fastest growing energy source on a percentage basis for over a decade. Different types of offshore wind turbines have also been developed for their advantages over their land-based counterparts, including more power output (produced by higher wind speed and larger size of the generator), less limitation on land space and less complaints on the visual and noise annoyances near the residential area. However, offshore environmental loads, which not only come from the wind but also from sea wave and current, can significantly affect the dynamic response of wind turbines and induce the vibrations of wind turbine structures. Excessive vibrations may produce variable stress, shorten the fatigue life of the structural components and reduce the power output of the wind turbines [1-6]. There are different types of offshore wind turbine foundation systems depending on the depth of sea where the wind turbine locates at, including mono pile, gravity foundation, tripod foundation, floating and deep sea concepts. Several floating offshore concepts have been proposed in the development of the deep sea wind turbines. Musial et al. [7] discussed the advantages and disadvantages of the platform topologies which can be classified by single- or multiple-turbine floaters or by the mooring method. A floating system consisting of multi turbines could possibly reduce the total weight for the large system ( $>20 \mathrm{MW}$ per system structure) but has higher construction cost than single-turbine floaters. Thus the single-turbine concept has been considered in most published papers. Henderson et al. [8] discussed various floating platform concepts and studied the triple (leg) floater with its preliminary designed mooring system for shallow offshore sites. Butterfield et al. [9] provided a framework for different platform architectures based on their static stability criteria, and pointed out that the platform architecture can be stated by the mooring methods. There are three commonly used mooring systems namely; catenary moorings, taut leg moorings and vertical tension leg, of which the vertical tension legs can be considered as a subset of taut leg mooring. Each mooring 
system has its own structure to achieve the platform's stability. For the catenary moored platform, Ballast is placed within the platform to lower the center of mass below the buoyancy centre. Different from the taut lag moored platform, additional buoyancy on the platform structure is generated by the mooring line tension. Pecher et al. [10] presented a comparison study of the quasi-static analysis of a single anchor leg mooring and a three legged catenary anchor leg system under the same reference load case. Guo et al. [11] performed a quasi-static analysis on the multicomponent mooring line and investigated the performances of the segments contained within water column and soil column during pretension and under service conditions.

Colwell et al.[12] found that the wind blowing over offshore wind turbines could cause parameter related sea wave loading on structure and developed a multi degree-of-freedom (DOF) tower model under the moderate and strong wind conditions. They introduced a tuned liquid column damper as an additional damping system to reduce the peak response of the tower system. Zhang et al. [13] developed a 13 DOFs tower-blade-drivetrain shallow water wind turbine model and considered both cases of gearbox and direct-drive system as different drive-train systems. Adhikari et al. [14] briefly introduced different foundations for wind turbine and studied the vibration of wind turbine towers on flexible foundations. The foundation was modelled as elastic supports with a combination of a rotational spring and a lateral spring. Ramachandran et al. [3] examined the coupled three-dimensional dynamic response of a tension leg platform floating offshore wind turbine using 17 DOFs, in which 6 DOFs for the platform motion and the rest for the wind turbine itself. Morison's equation and the unsteady blade-element-momentum (BEM) theory were used to calculate the three dimensional wind and wave loadings applied on the system. Noticeable influences were found from the platform to the tower due to the wind shear and the turbulence effects. Wei et al.[15] carried out both static and dynamic analyses on the jacket support wind turbine structures under 
regular and irregular waves. A $10^{\text {th }}$ order stream function theory was used to model the large regular waves and the linear wave theory to describe the irregular waves. Koukoura et al. [16] presented a cross wind fatigue analysis of the wind turbine by considering the wind-wave misalignment conditions, and studied the relationship between the side-side fatigue loads of the tower structure and the wind-wave misalignment conditions under different damping conditions. Karimirad et al. [4] analysed the dynamic structural response of a spar-type 5MW wind turbine under harsh and operating environmental conditions. By performing a comparative study of the wave and wind induced response, they found that the wind could induce the mean values of the dynamic response and wave induce the standard deviations of the response.

This paper studies the dynamic response of a 5MW spar-type offshore direct-drive wind turbine in deep sea conditions. The contributions of this paper lie in two aspects: First of all, the effects of aerodynamic and hydrodynamic excitations on a spar-type direct-drive wind turbine structure are investigated by carrying out a series of time domain numerical simulations. The response of the platform with tower structure with the current induced only, the current and wave induced, and the current, wave and wind induced are compared to show the dominant effects under different types of excitations. The misalignment of the wind, wave and current directions is also considered to show its effect. Secondly, a dynamic model of the direct-drive drive-train system is incorporated into the dynamic model of the platform with tower structure to show the interaction effect between the drive-train system and the tower structure. The nacelle is considered as a point mass attached on the top of the tower firstly. Then the dynamic interaction between the drive-train system and the nacelle is considered to form a combined model of a spar-type supporting platform wind turbine. This paper is organized into five sections. Section 2 presents the dynamic models of the drive-train system and of the floating 
platform with tower structure. Various excitations are discussed in Section 3. Section 4 gives numerical simulations and discussions. The conclusion is drawn in Section 5.

\section{Dynamic model}

A catenary moored spar-type direct-drive wind turbine based on the NREL $5 \mathrm{MW}$ wind turbine with easy access to the system parameters is chosen in this paper as it has been used in studying the vibration behaviour of offshore wind turbines [4, 17-19]. The spar supported platform is a shaped cylinder with ballast inside and mooring system attached on it. A simple sketch of the model is shown in Figure 1. A total of 8 DOFs system, which consists of 4 DOFs free-free end model of the wind turbine structure and 4 DOFs model of the drive-train system, will be developed for investigating the effects of hydrodynamic and aerodynamic excitations on the dynamic response of the spar-type floating direct-drive wind turbine. Two coordinate systems, a moving-local $(X, Y, Z)$ coordinate system and a fixed-global $\left(X^{\prime}, Y^{\prime}, Z^{\prime}\right)$ coordinate system, are used to describe the motion of the drive-train system and the motion of the floating platform with tower structure. The nacelle is first considered as a non-rotating mass point fixed on the top of the tower thus only the thrust force from the blades will be considered in the dynamic analysis of the wind turbine structure. Then the rotating interaction between the drive-train system and the nacelle will be discussed to examine the interaction effects. 

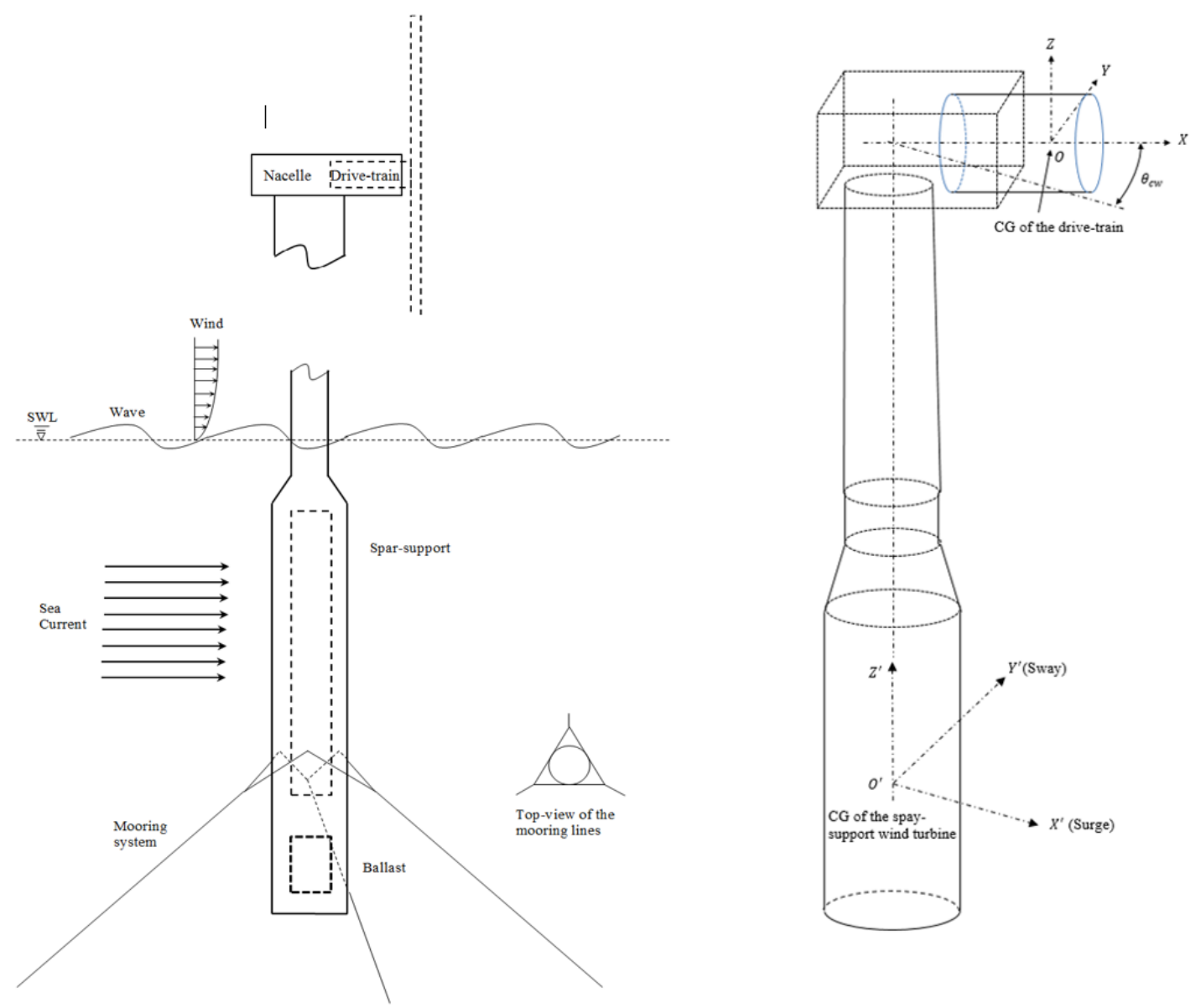

Figure 1 A simple sketch of the spar supported wind turbine and the global and local coordinate systems

This paper aims to study the vibration behaviour of the spar-type wind turbine structure under the aerodynamic and hydrodynamic excitations, which are generated from wind, sea current, wave, mooring and buoyancy. The interaction between the drive-train system and the platform system will also be considered. As a result, a number of assumptions are made to focus on the primary points without redundancies:

- The spar supported platform with tower structure is considered as a long rigid floating body under deep sea conditions. Its deformation and flexibility is ignored by considering its floating nature.

- Only the displacements and the inclination angles of the platform with tower structure in surge and sway directions are considered in the analysis. The displacement in heave 
direction is ignored as it is less important than those in the other directions according to the preliminary result of numerical simulations.

- In deep sea, waves are mainly generated by the wind and tend to travel in the same direction as the wind blows. Accordingly, it is assumed that the wave direction is always the same as the wind direction, except for the case of misalignment to be considered.

- The current direction is assumed to be in the surge direction. However it is noticed that the wind and wave directions may not always be the same as the current direction. The effect of the angle between the wind, wave and current directions $\theta_{\mathrm{wc}}$ is introduced to reflect the difference in these directions.

- The dynamic effects associated with the mass, damping, and fluid acceleration on the mooring lines are neglected. Only the relationship between the displacement and force is used to indicate the external effects on the platform.

- Only the normal operational conditions are studied. The extreme and fault conditions are not considered for the wind turbine system.

\subsection{The dynamic model of the drive-train system}

A nonlinear system of 4 DOFs $\left(y, z, \theta_{y}, \theta_{z}\right)$ in a moving-local $(X, Y, Z)$-coordinate system with origin at the centre of gravity (CG) of the drive-train system is used to described the motion of the drive-train system. The drive-train system for a direct-drive wind turbine considered consists of a uniform hollow shaft which is supported by two isotropic bearings. A rotor and the hub with blades are attached on the shaft to form the drive-train system, as discussed in [20]. Figure 2 shows a simplified schematic of the drive-train system. The interaction between the drive-train system and the nacelle mainly come from the bearings and 
generator through variable internal forces $[19,21]$. The main source of vibration in the directdrive generator is the unbalanced magnetic pull (UMP) force. The force analysis of the drivetrain system and its free body diagram are shown in Figure 3.

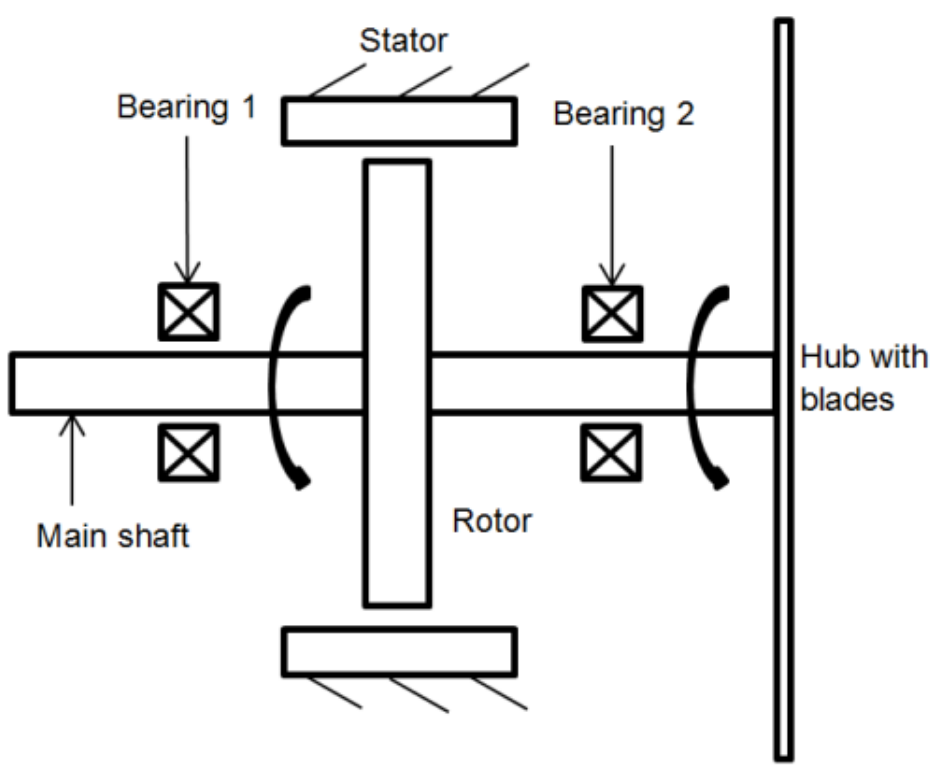

Figure 2. A simplified schematic of the drive-train system [20]

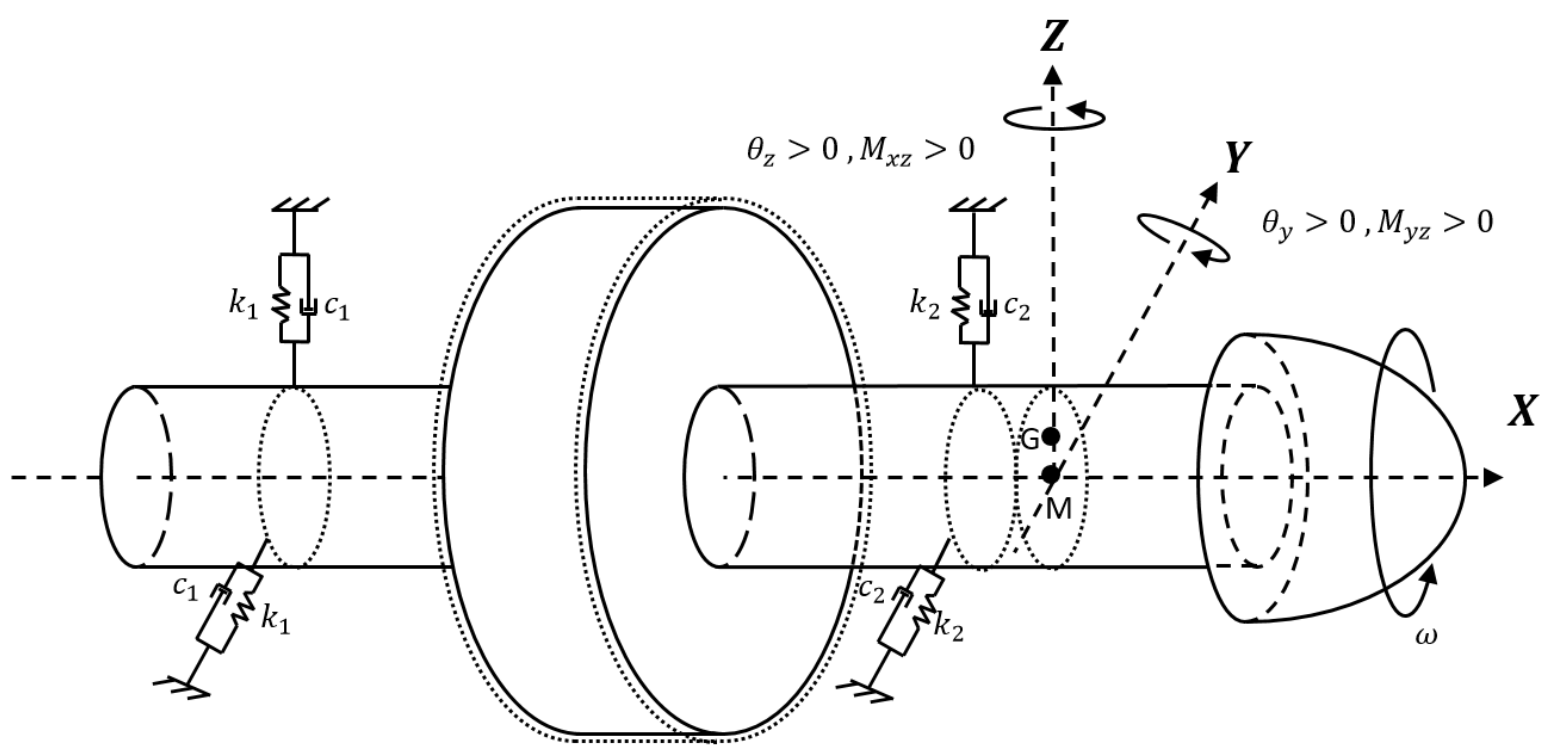




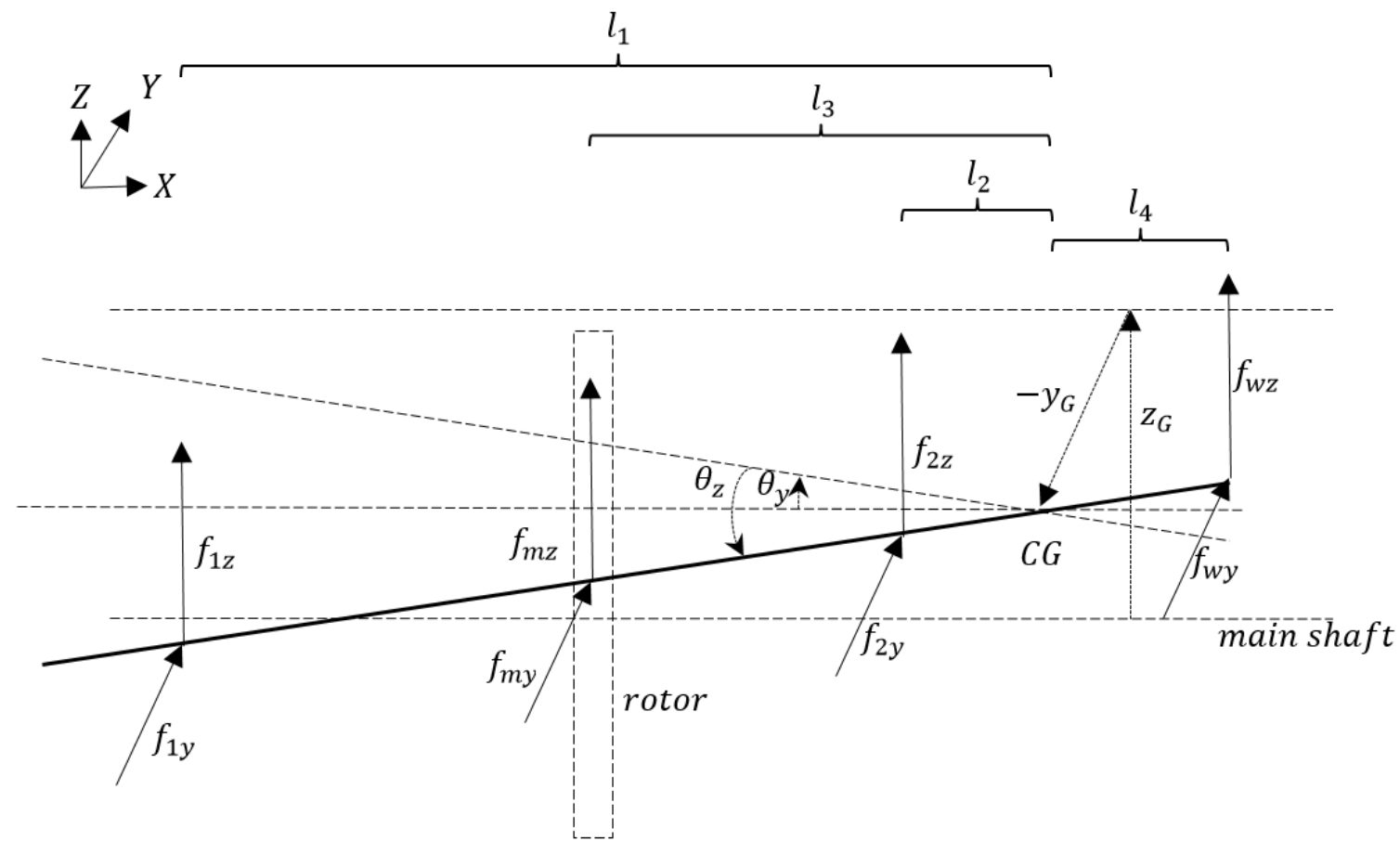

Figure 3. Schematic of the drive train system and its free body diagram, where the CG represents the centre of gravity of the drive-train system [20]

By applying Newton's law of motion, the equations of motion of the drive-train system can be obtained as

$$
\begin{gathered}
m \ddot{y}+c_{11} \dot{y}+c_{12} \dot{\theta}_{z}+k_{13} y+k_{14} \theta_{z}=m e \omega^{2} \cos (\omega t)+f_{m y}+f_{w y} \cos \left(\omega_{w} t\right) \\
m \ddot{z}+c_{11} \dot{z}-c_{12} \dot{\theta}_{y}+k_{13} z-k_{14} \theta_{y}=m e \omega^{2} \sin (\omega t)+f_{m z}+f_{w z} \cos \left(\omega_{w} t\right) \\
I \ddot{\theta}_{z}+I_{p} \omega \dot{\theta}_{y}+c_{21} \dot{y}+c_{22} \dot{\theta}_{z}+k_{23} y+k_{24} \theta_{z}=\left(I_{p}-I\right) \tau \omega^{2} \cos (\omega t+\beta)+l_{3} f_{m y}-l_{4} f_{w y} \\
I \ddot{\theta}_{y}-I_{p} \omega \dot{\theta}_{z}+c_{21} \dot{z}-c_{22} \dot{\theta}_{y}+k_{23} z-k_{24} \theta_{y}=\left(I_{p}-I\right) \tau \omega^{2} \sin (\omega t+\beta)+l_{3} f_{m z}-l_{4} f_{w z}
\end{gathered}
$$

where $(y, z)$ represent the displacement of the centre of geometry and $\left(\theta_{y}, \theta_{z}\right)$ denote the inclination angle of centre of geometry, $\omega$ stands for the rotational speed of the drive-train system, $e$ is the eccentricity, $\tau$ is the skew angle and $\beta$ is the angle between the principal axis and the direction of the unbalanced mass. $m, I$ and $I_{p}$ represent the total mass, moment of inertia and polar moment of inertia of the drive-train system. In addition, $c_{i j}$ and $k_{i j}$ are the damping coefficient and stiffness. Furthermore, $\left(\mathrm{F}_{\mathrm{wy}}, \mathrm{F}_{\mathrm{wz}}\right)$ represent the wind forces in $\mathrm{y}$-axis 
and z-axis direction considered as the external excitations which play an important role in the rotor dynamics [22], such fluctuating external forces can be expressed as $F_{w y}=f_{w y} \cos \left(\omega_{w} t\right)$, $F_{w z}=f_{w z} \cos \left(\omega_{w} t\right)$, where $f_{w y}, f_{w z}$ are the magnitudes of the fluctuating force and $\omega_{\mathrm{w}}$ is the frequency. And $\left(f_{m y}, f_{m z}\right)$ denote the components of the UMP force in $y$ and $z$ directions, respectively. More details can be found in reference [20]. Eq.(5) determines the vibrations of the drive-train system. It will be incorporated with the dynamic model of the spar-type platform to study the dynamic interaction induced response in the wind turbines.

\subsection{The dynamic model of the spar-type platform with tower structure}

The spar-type platform with tower structure is assumed to be a rigid body for the sake of simplicity. A 4 DOFs system $\left(x^{\prime}, y^{\prime}, \theta_{x}{ }^{\prime}, \theta_{y}{ }^{\prime}\right)$ is used to describe the motion of the platform in the fixed-global $\left(X^{\prime}, Y^{\prime}, Z^{\prime}\right)$-coordinate system. The coordinates $\left(x^{\prime}, y^{\prime}\right)$ define the translational motion of the spar supported tower in $X^{\prime}$ and $Y^{\prime}$ directions, respectively. The coordinates $\left(\theta_{x}{ }^{\prime}, \theta_{y}{ }^{\prime}\right)$ indicate the rotational motion of the platform about $X^{\prime}$ and $Y^{\prime}$ directions. Many existing studies have assumed that the damping ratio of the system to be $2 \%$. Then the damped and undamped natural frequencies of the system would be equal for such a low critical damping ratio. By using the Newton's Second Law of Motion, the equation of motion for the platform with tower structure can be written as:

$$
\begin{aligned}
& m^{\prime} \ddot{x}^{\prime}=F_{\text {current_x }} x^{\prime}+F_{\text {wind_ } x^{\prime}}+F_{\text {wave_}} x^{\prime}+F_{\text {mooring } \_x^{\prime}}+F_{\text {interaction } \_} x^{\prime} \\
& m^{\prime} \ddot{y}^{\prime}=F_{\text {current_ } y^{\prime}}+F_{\text {wind } \_y^{\prime}}+F_{\text {wave_} y^{\prime}}+F_{\text {mooring } y^{\prime}}+F_{\text {interaction } \_y^{\prime}} \\
& I^{\prime} \ddot{y_{y^{\prime}}}=M_{\text {current_y } y^{\prime}}+M_{\text {wind_y } y^{\prime}}+M_{\text {wave } y^{\prime}}+M_{\text {mooring_y }} y^{\prime}+M_{\text {bounacy } y^{\prime}}+M_{\text {interaction } y^{\prime}} \\
& I^{\prime} \ddot{\theta}_{x^{\prime}}=M_{\text {current_x } x^{\prime}}+M_{\text {wind_x } x^{\prime}}+M_{\text {wave } \_x^{\prime}}+M_{\text {mooring_x } x^{\prime}}+M_{\text {bounacy_x } x^{\prime}}+M_{\text {interaction } \_x^{\prime}}
\end{aligned}
$$


where $m^{\prime}$ and $I^{\prime}$ are the total mass and moment of inertia of the wind turbine including the nacelle (as a point mass). The interaction forces and moments are the equivalent response generated from the force response in the drive-train system, which can be determined by

$$
\begin{gathered}
F_{\text {interaction } \_x^{\prime}}=f_{x} \cos \theta_{c w}+\sum f_{i y} \sin \theta_{c w} \\
F_{\text {interaction } \_y^{\prime}}=f_{x} \sin \theta_{c w}+\sum f_{i y} \cos \theta_{c w} \\
M_{\text {interaction_ } y^{\prime}}=\left(f_{x} \cos \theta_{c w}+\sum f_{i y} \sin \theta_{c w}\right) h_{o o^{\prime}}-\sum f_{i z}\left(l_{o o^{\prime}}+l_{i}\right) \sin \theta_{c w} \\
M_{\text {interaction_ } x^{\prime}}=-\left(f_{x} \sin \theta_{c w}+\sum f_{i y} \cos \theta_{c w}\right) h_{o o^{\prime}}+\sum f_{i z}\left(l_{o o^{\prime}}+l_{i}\right) \cos \theta_{c w}
\end{gathered} \text { for } i=1,2,3
$$

where $f_{x}$ represents the thrust force on the drive-train system, $\left(f_{i x}, f_{i y}\right)$ denote the force response at the specific positions (Bearing 1 , Bearing 2 and the generator), $l_{o o^{\prime}}$ and $h_{o o^{\prime}}$ are the horizontal and vertical distance between the CG of the drive-train system and the CG of the platform.

In substituting the equations of motion of the drive-train system in the local coordinate system into the global coordinate system, the displacement of the drive-train system has the following relationship between the two coordinate systems

$$
\begin{aligned}
& y=y_{\text {local }}-y_{\text {global }} \quad \theta_{z}=\theta_{z_{-} \text {local }}-\theta_{z_{-} \text {global }} \\
& z=z_{\text {local }}-z_{\text {global }} \quad \theta_{y}=\theta_{y_{\_} \text {local }}-\theta_{y_{-} \text {global }}
\end{aligned}
$$

where

$$
\begin{gathered}
y_{\text {global }}=y^{\prime}+l_{o o^{\prime}} \theta_{z^{\prime}}, \quad \theta_{z_{-} g l o b a l}=\theta_{z^{\prime}}, \\
z_{\text {global }}=z^{\prime}+h_{o o^{\prime}}\left(2-\cos \theta_{y^{\prime}}-\cos \theta_{x^{\prime}}\right), \quad \theta_{y_{-} g l o b a l}=\theta_{y^{\prime}} .
\end{gathered}
$$

When the drive-train system is modelled as a point mass, only 4 DOFs in the global coordinate system will be considered and Eq.(6) will be studied to show the motion of the platform with tower structure. Only the thrust force on the drive-train system will be transformed to the top of the tower, thus the interaction forces and moments in Eq.(6) will be equal to zero as they are considered as internal forces. In this case, there is no dynamic interaction between the drivetrain system and tower structure. When the interaction between the drive-train system and the nacelle is induced, the dynamic force between the drive-train system and the nacelle will be 
considered as external forces for the tower structure. By substituting Eq.(7) into Eq.(5) and combining the resultant equations with Eq.(6), the equations of motion would have 8 DOFs for the whole wind turbine structure which can then be numerically solved in Matlab using ODE45 solver. Accordingly, the dynamic response of the wind turbine can be examined.

The main components and system parameters of a 5MW direct-drive wind turbine studied in this paper, such as the platform, the tower and the drive-train system, are adapted from the NREL 5MW wind turbine with direct-drive system $[4,18,23,24]$. The spar supported platform is considered as a cylinder structure with a length of $120 \mathrm{~m}$. The main system parameters of the turbine structure are given in Table 1 and Table 2. The whole turbine structure is a non-uniform mass structure since the ballast is located within the structure to lower the CG in order to reduce the vibration of the system. The turbine structure is considered as a rigid body and the deflection is ignored for the sake of brevity. The mooring system is regarded as a spring system with variable stiffness depending on its displacement.

Table 1 Main parameters of the spar supported wind turbine $[4,18]$

\begin{tabular}{|l|l|l|}
\hline Description & Units & Value \\
\hline Total weight(wind turbine) & $\mathrm{kg}$ & $8,329,230$ \\
\hline Pitch inertia about the CG(wind turbine) & $\mathrm{kg} \cdot \mathrm{m}^{2}$ & $2.2 \times 10^{10}$ \\
\hline Hub height & $\mathrm{m}$ & 90 \\
\hline Spar supported length above the SWL & $\mathrm{m}$ & 10 \\
\hline Spar supported length below the SWL & $\mathrm{m}$ & 120 \\
\hline Diameter of the spar support above the taper & $\mathrm{m}$ & 6.5 \\
\hline Diameter of the spar support below the taper & $\mathrm{m}$ & 9.4 \\
\hline Location of mooring below the SWL & $\mathrm{m}$ & 70 \\
\hline
\end{tabular}




\begin{tabular}{|l|l|l|}
\hline Location of the CG below the SWL & $\mathrm{m}$ & 78.61 \\
\hline Location of buoyancy below the SWL & $\mathrm{m}$ & 60 \\
\hline Drag coefficient & - & 0.6 \\
\hline SWL: Sea Water Level & & \\
\hline
\end{tabular}

Table 2 System parameters for the drive-train system [18, 19, 23-27]

\begin{tabular}{|c|c|c|c|}
\hline Symbol & Description & Units & Value \\
\hline $\mathrm{m}$ & Total mass of the rotor system & ton & 174.68 \\
\hline $\mathrm{L}$ & Length of the shaft & $\mathrm{m}$ & 3 \\
\hline Rs & Inner radius of the stator & $\mathrm{m}$ & 3.185 \\
\hline$\Delta \mathrm{r}$ & Average air gap & $\mathrm{mm}$ & 6.36 \\
\hline $\mathrm{h}$ & Length of the magnet & $\mathrm{m}$ & 1.72 \\
\hline Ip & Polar moment of inertia & $\mathrm{kg} \cdot \mathrm{m}^{2}$ & $3.54 \times 10^{7}$ \\
\hline I & Moment of inertia & $\mathrm{kg} \cdot \mathrm{m}^{2}$ & $1 \times 10^{5}$ \\
\hline \multirow[t]{4}{*}{$\mathrm{p}$} & Number of the pole pair & & 60 \\
\hline & Distance along shaft from hub centre to Bearing 1 & $\mathrm{~m}$ & 2.65 \\
\hline & Distance along shaft from hub centre to Bearing 2 & $\mathrm{~m}$ & 0.65 \\
\hline & Distance along shaft from hub centre to rotor centre & $\mathrm{m}$ & 1.65 \\
\hline$l_{o o^{\prime}}$ & $\begin{array}{l}\text { Horizontal distance between the CG of the drive- } \\
\text { train system and the CG of the platform }\end{array}$ & $\mathrm{m}$ & 2 \\
\hline$h_{o o^{\prime}}$ & $\begin{array}{l}\text { Vertical distance between the CG of the drive-train } \\
\text { system and the CG of the platform }\end{array}$ & $\mathrm{m}$ & 168.61 \\
\hline
\end{tabular}

\section{External excitations}




\subsection{Aerodynamic excitation}

Aerodynamic excitations, mainly in the form of wind excitations, are discussed based on two parts of the wind turbine, the tower and the blades. For the wind excitation on the tower part, the long term variability of wind force can be simply calculated by using a mean wind speed. A common wind shear model is used to represent the mean speed,

$V_{(z)}=V_{H}\left(\frac{z}{H}\right)^{\alpha}$

where $V_{(z)}$ is the mean wind speed at the altitude $z, V_{H}$ is the reference wind velocity at the reference altitude $H$ (normally $H=10 \mathrm{~m}$ ), $\alpha$ is the wind shear exponent $(\alpha=0.11)$. The drag force of fluids passing through the tower structure is given by:

$F_{w}=\frac{1}{2} \rho_{a} V_{r(z)}^{2} C_{d} A_{(z)}$

where $\rho_{a}$ is the air density, $V_{r(z)}$ is the relative velocity of the wind and the structure, $C_{d}$ is the drag coefficient of the structure and $A_{(z)}=d_{e} \times d z$ is the equivalent characteristic surface area. The spar's motion is normally assumed to be small and thus the relative velocity at elevation $z$ is close to its wind velocity $V_{r(z)} \approx V_{(z)}$.

The wind excitation on the blades consists of a thrust force and a high torque in the generator. The thrust force can be transformed directly to the tower through the drive-train system, while radial forces can be produced due to the rotational motion induced by the high torque. The radial force responses of the drive-train system are normally generated at the bearings (bearing forces) and rotor-stator position (the UMP). In order to control the rotating operation and the torque generated, a blade-pitch control system is widely used to limit the above rated rotating speed. Since the control system will not be discussed in this paper, the drive-train system is assumed to operate at the rated rotating speed corresponding to the wind speed. For the aboverated wind speed, the rotating speed will be limited at the rated speed by using the blade-pitch control system. The turbine cut-in and cut-out wind speeds are $4 \mathrm{~m} / \mathrm{s}$ and $25 \mathrm{~m} / \mathrm{s}$, and the rated 
rotating speed is set at $12 \mathrm{rpm}$. When the wind speed is beyond the cut-out speed, the drivetrain system would stops rotating in order to survive under extreme weather conditions. The tower shadow can be ignored in some cases [28], thus the blade and tower interaction will not be considered in this paper. A sample blade model was simplified and the blade parameters of the blade was implemented into the software HAWC2 to obtain the relationship between the blade rotating speed and the wind speed and the relationship between the thrust force from the blades to the drive-train system and the wind speed $[4,18]$. This paper will adopt the relationship between the thrust force and wind speed given in $[4,18]$ in the modelling of aerodynamic excitation.

\subsection{Hydrodynamic excitations}

The hydrodynamic excitations of the offshore wind turbines mainly come from wave, sea current and buoyancy, which will be discussed in the following subsections.

\subsubsection{Wave excitation}

Waves in deep sea environment can be assumed as a nearly linear superposition of harmonic components according to the linear theory of waves. The linear wave theory describes the linear gravity waves on the surface of a homogeneous fluid layer which has a uniform mean depth. The waves with longer periods have a higher celerity than those with shorter periods. A complex three dimensional short crested surface elevation can be generated within or close to the area where the waves are generated. Most of the standard models of the sea waves are characterized by the power spectral density function (PSDF). The sea surface elevation is a representative parameter of the sea state. The distribution of the sea wave is of Gaussian-type

random characteristic which is regarded as an infinite number of independent waves with different wave heights and wave periods. A fetch condition which the wind blows over uninterrupted distance without any significant direction change is considered for the 
approximation of the sea surface elevation spectrum [29]. The Pierson-Moskowitz (PM) spectrum was first developed to define the relationship of the energy with wave frequency, by assuming that the wave is in equilibrium with the wind when it is blowing steadily over a large area for a long time, which has been known as the fully developed sea [30]. However, the sea waves were found never to be fully developed from the data which were collected in the Joint North Sea Wave Project (JONSWAP) [12]. The JONSWAP spectrum was then used by introducing an additional factor to improve the wave modelling. The increase of peak in the spectrum and the frequency shift of the maximum spectrum was also taken into account [31]. The long-term variability of wave loads can be defined by two wave spectral parameters: the significant wave height $\left(H_{s}\right)$, and the peak period $\left(T_{p}\right)$. Johannessen et al. [32] used a Weibull distribution to describe the significant wave height and a lognormal distribution to introduce its peak period, which was correlated with the given mean wind speed at $10 \mathrm{~m}$ height and the significant wave height. The expected value of the significant wave height and the expected value of the peak period are

$E\left(H_{s}\right)=\beta \Gamma\left(\frac{1}{\alpha}+1\right)$

$E\left(T_{p}\right)=\left(4.883+2.68 H_{s}^{0.529}\right) \times\left\{1-0.19\left[\frac{v-\left(1.764+3.426 H_{s}^{0.78}\right)}{1.764+3.426 H_{s}^{0.78}}\right]\right\}$

The wave model will be considered with different wind speeds to investigate the dynamic response of the wind turbine under three main wind conditions, namely weak, moderate and strong winds. The wind and wave conditions for all cases are presented in Table 3.

Table 3 Parameters for wind and sea conditions

\begin{tabular}{|c|c|c|c|}
\hline $\mathrm{V}_{\text {mean }}(\mathrm{m} / \mathrm{s})$ & $\mathrm{H}_{\mathrm{s}}(\mathrm{m})$ & $\mathrm{T}_{\mathrm{p}}(\mathrm{s})$ & Condition \\
\hline 8 & 2.52 & 9.848 & weak \\
\hline 11 & 3.01 & 10.037 & \\
\hline 14 & 3.55 & 10.267 & \\
\hline
\end{tabular}




\begin{tabular}{|c|c|c|l|}
\hline 16 & 3.94 & 10.437 & moderate \\
\hline 17 & 4.14 & 10.908 & \\
\hline 21 & 4.98 & 11.023 & \\
\hline 25 & 5.88 & 11.321 & \\
\hline 30 & 7.1 & 11.9 & strong* \\
\hline * Drive-train system stops rotating \\
\hline
\end{tabular}

A JONSWAP spectrum is used to describe the wave and takes the form of

$S_{\eta \eta}(\omega)=\frac{5}{16} H_{S}^{2} \omega_{p}^{4} \omega^{-5} \exp \left[-\frac{5}{4}\left(\frac{\omega_{p}}{\omega}\right)^{4}\right] \gamma^{\exp \left[-\frac{\left(\omega-\omega_{p}\right)^{2}}{2 \sigma^{2} \omega_{p}^{2}}\right]}$

where $\eta$ is the function of water surface elevation, $\gamma$ is the peak enhancement factor $(\gamma=3.3$

for deep sea), $\omega_{p}=\frac{2 \pi}{T_{p}}$ is the peak wave frequency, $\omega=\frac{2 \pi}{T_{m}}$ is the circular wave frequency and $T_{m}$ is the mean wave period. The spectrum defines a stationary Gaussian process with its standard deviation being equal to 1 . The mean wave period $T_{m}$ and the zero-up-crossing wave period $T_{z}$ are related to its peak period $T_{p}$ and its peak enhancement factor $\gamma$, as follows

$T_{p}=1.2859 T_{z}$
$T_{m}=1.0734 T_{z}$ for $\gamma=3.3(12 \mathrm{a})$

and

$\sigma= \begin{cases}0.07 & \omega \leq \omega_{p} \\ 0.09 & \omega>\omega_{p}\end{cases}$

The total wave force acting on the spar support can be calculated by the equation

$f_{\text {wave }}(t)=\int_{0}^{d_{w}} p(z, t) d z$

where $d_{w}$ is the water depth (from the SWL to sea bed), $z$ is the vertical coordinate axis, $p(z, t)$ is the wave force acting on the structure which can be calculated by using the linearized Morison equation as following 
$p(z, t)=K_{d} \sqrt{\frac{8}{\pi}} \sigma_{v} v(z, t)+K_{m} a(z, t)$

with

$K_{d}=\frac{1}{2} C_{d} \rho_{w} d_{e}$

$K_{m}=\frac{1}{4} C_{m} \rho_{w} \pi d_{e}^{2}$

where $C_{d}$ is the drag coefficient, $C_{m}$ is the inertia coefficient, $d_{e}$ is the equivalent characteristic diameter of spar support and $\rho_{w}$ is the sea water density. According to the linear dispersion relationship [33], the wave property under deep sea condition follows

$\frac{d_{w}}{\lambda}>\frac{1}{2}$

And the relation of the circular wave frequency and the wave number can be found as

$\omega^{2} \approx \mathrm{gk}$

$\lambda=\frac{2 \pi}{k}$

where $k$ is the wave number and $\lambda$ is the wave length. The relationship of the horizontal velocity $v(z, t)$ and acceleration $\dot{v}(z, t)$ of the water particle in the deep sea environment and the wave elevation can be determined by using the linear wave theory,

$v(z, t)=T_{v}(z) \eta(t)$

$\dot{v}(z, t)=T_{a}(z) \dot{\eta}(t)$

where

$T_{v}(z)=\omega e^{k z}$

$T_{a}(z)=\omega^{2} e^{k z}$

The standard deviation of the velocity at altitude $z$ (from the SWL) can be obtained as

$\sigma_{v}(z)=\left[\int_{0}^{\omega}\left|T_{v}(z)\right|^{2} S_{\eta \eta}(\omega) d \omega\right]^{1 / 2}(1$

Substituting the relevant terms into Eq. (13) yields the total wave force acting on the structure,

$f_{w}(t)=\left\{\int_{0}^{d_{w}}\left[K_{d} \sqrt{\frac{8}{\pi}} \sigma_{v}(z) T_{v}(z)+K_{m} T_{a}(z)\right] d z\right\} \eta(t)$ 
A sample function of the random water surface elevation can be described by the trigonometric polynomial [34] as

$\eta(t)=\sum_{k=1}^{n} \sqrt{S_{\eta \eta}(\omega) d \omega}\left(A_{1 k} \cos \left(\omega_{k} t\right)+A_{2 k} \sin \left(\omega_{k} t\right)\right)(21)$

where $A_{1 k}, A_{2 k}$ for $k=1,2, \ldots, n$ are mutually independent standard normal variables and $\omega_{\mathrm{k}+1}=\omega_{\mathrm{k}}+\Delta \omega$, with $\Delta \omega$ being an infinitesimal frequency step. A truncation at the upper frequency $\omega_{\mathrm{u}}$ can be made to neglect the small variance at higher frequency on the residual contribution, where $\int_{\omega_{u}}^{\infty} S_{\eta \eta}(\omega) d \omega \ll 1$. In this paper, the upper frequency is set $\omega_{u}=2 \pi$, which gives $\int_{\omega_{\mathrm{u}}}^{\infty} \mathrm{S}_{\eta \eta}(\omega) \mathrm{d} \omega \approx 0.00013$ and the resulting regularity factor is about 0.3461 for the moderate condition. Other general parameters are the air density $\rho_{\mathrm{a}}=1.2 \mathrm{~kg} / \mathrm{m}^{3}$ and sea water density $\rho_{\mathrm{w}}=1029 \mathrm{~kg} / \mathrm{m}^{3}$. The PSDF for the three wind conditions can be seen in Figure 5. The time history of the surface elevation of the sea and the loads on the platform under moderate condition is shown in Figure 6. The detailed sample data of the random wave will be input into the simulation to obtain the non-linear displacement and forces. It is noted that the wave at low level of sea surface may lead to a backward direction force acting on the structure (due to linear wave theory). The same irregular wave under certain sea conditions will be used to investigate the relative effect of different excitations on wind turbine and the effect of the interaction between the drive-train system and the tower structure. 


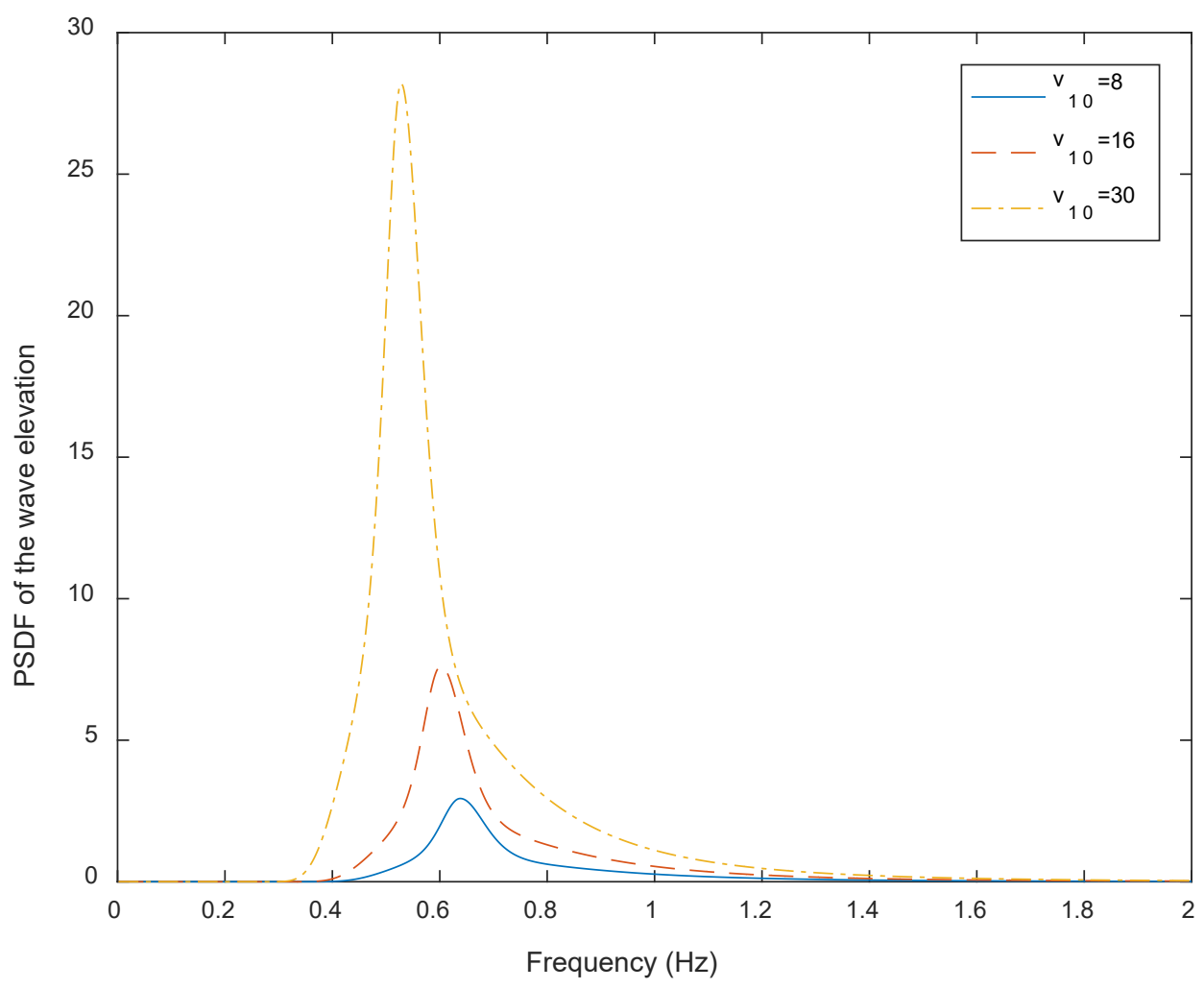

Figure 4 PSDF of the wave under different sea conditions 

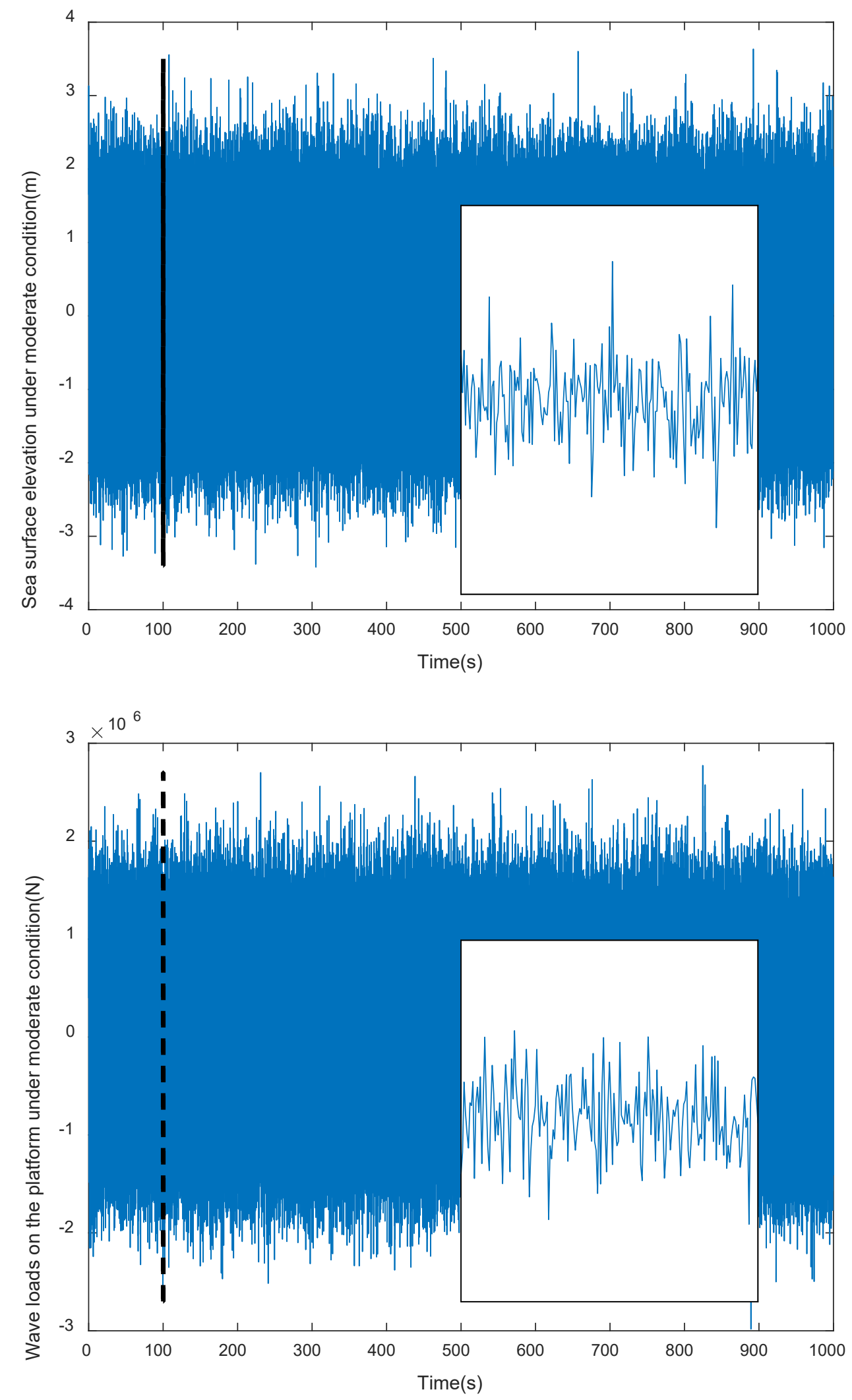

Figure 5 Time history of the random surface elevation of the sea and the random loads on the platform under moderate condition, (a) sea surface elevation, (b) the loads on the platform 


\subsubsection{Current excitation}

For a long structure sitting in an offshore environment, the current load can be an important source of hydrodynamic damping in some cases[6]. The sea current is a complex component varying with the sea depth, global location, time and other factors. To simplify the effect of the current loads on the model, an average current velocity of $V_{c}=0.9 \mathrm{~m} / \mathrm{s}$ with a fixed direction is used in the present paper. The force per unit length acting on the spar can be predicted by using the Morison equation as,

$F_{c}(z)=\frac{1}{2} \rho_{w} C_{d} V_{r c}^{2} d_{e}(z)+\frac{\pi}{4} \rho_{w} C_{m} \dot{V}_{r c} d_{e}(z)^{2}(22)$

where $\rho_{w}$ is the sea water density, $V_{r c}$ is the relative velocity of the current and the structure, $C_{d}$ and $C_{m}$ are the drag coefficient and inertia coefficient of the structure and $d_{e}$ is the equivalent characteristic diameter of the cylinder structure. The spar's motion is usually assumed to be small and thus the relative velocity at elevation $z$ is close to the sea current velocity $V_{r c} \approx V_{c}$.

\subsubsection{Buoyant forces}

The buoyant force is the only force to support the whole wind turbine floating on the sea level, and is variable due to the change in longitudinal force and the sea surface. As made in the assumption, the displacement in the heave direction is ignored, the buoyant force is thus balanced by the weight of the structure and the force in the heave direction. The centre of buoyancy is lower than the CG of the wind turbine due to the ballast which can help the platform achieve its stability. The effect of the buoyant force on the moment of the spar support for small angle inclination cannot be ignored and will be investigated. The buoyant force and resultant bending moment can be calculated as, 
$F_{\text {buoyancy_z }} z^{\prime}=m^{\prime} g+F_{\text {interaction } \_} z^{\prime}$
$M_{\text {buoyancy_x }} x^{\prime}=F_{\text {buoyancy } z^{\prime}} \times l_{b-C G} \times \theta_{x^{\prime}}$
$M_{\text {buoyancy_y }}=F_{\text {buoyancy_z }} \times l_{b-C G} \times \theta_{y^{\prime}}$

where $l_{b-C G}$ is the distance between the center of buoyancy and the CG of the wind turbine.

\subsection{Mooring system}

The parameters of the mooring system in this present study are adapted from Karimirad and Moan's design [4]. Table 4 summarises the mooring parameters and the mooring layout of the wind turbine can be found in reference [18]. Three sets of mooring lines are attached on the circumference of the spar with two segments for each. The segments are used to provide yaw stiffness. Each adjacent line is 120 degree apart, and thus the resultant stiffnesses of the surge motion and sway motion are different. The force-displacement relationship of such a mooring system acting on the spar support is nonlinear, as simulated by Sethuraman et al. [18].

Table 4 Mooring system properties [18]

\begin{tabular}{|l|l|l|}
\hline Description & units & value \\
\hline Sea depth & $\mathrm{m}$ & 320 \\
\hline Depth to mooring line attached on the spar below SWL & $\mathrm{m}$ & 70.0 \\
\hline Radius to mooring lines from platform centreline & $\mathrm{m}$ & 853 \\
\hline Unstretched mooring line length & $\mathrm{m}$ & 902.2 \\
\hline Mooring line diameter & $\mathrm{m}$ & 0.09 \\
\hline Clump mass & $\mathrm{kg}$ & 17,253 \\
\hline Equivalent mooring line mass density & $\mathrm{kg} / \mathrm{m}$ & 42.5 \\
\hline Equivalent mooring line weight in water & $\mathrm{N} / \mathrm{m}$ & 381.8 \\
\hline
\end{tabular}

\section{Numerical simulations and discussions}




\subsection{Current, wave and wind induced response}

The effects of different loads on the offshore wind turbine are firstly examined for comparison purpose. The nacelle and its components are considered as a point mass attached on the top of the tower structure, the current, wave and wind are all assumed in the surge direction in this subsection. The nacelle's performance clearly shows the motion of the wind turbine, which involves both displacement and rotational response of the spar supported platform, and its standard deviation. The time history of the nacelle motion subjected to sea current only, current and wave coupled excitation, and a combination of the current, wave and wind actions, under three different sea conditions as defined in Table 3, is shown in Figure 7. Since the current excitation is independent of the sea condition, the nacelles' performance in all three conditions is found to be same. The maximum displacement is $5.35 \mathrm{~m}$, the mean displacement is $2.67 \mathrm{~m}$ and the standard deviation is $1.49 \mathrm{~m}$. A summary of the performance of the nacelle in the surge direction under the three sea conditions with different considerations is given in Table 5. The nacelle's mean displacement is increased by no more than $1 \mathrm{~m}$ when only the wave is involved but it can be increased up to $18.7 \mathrm{~m}$ when both wave and wind are involved, meanwhile the change of its standard deviation is significant under wave involved excitations, up to 16.32 . In contrast, the change is small when both wave and wind involved, only up to 2.5 . The maximum displacement is related to both the mean value and the standard deviation. The results indicate the nacelle's mean displacement response is primarily wind induced and its standard deviation is primarily wave induced.

The offshore floating wind turbine design standard mentioned by Jonkman [6] requires the consideration of the wind and wave misalignments up to 30 degree. The simulation results with misalignment of $\pm 8^{\circ}$ and $\pm 30^{\circ}$ indicate the same conclusion for the excitation's effect as above. Thus the misalignment will not be further discussed in the following section. 


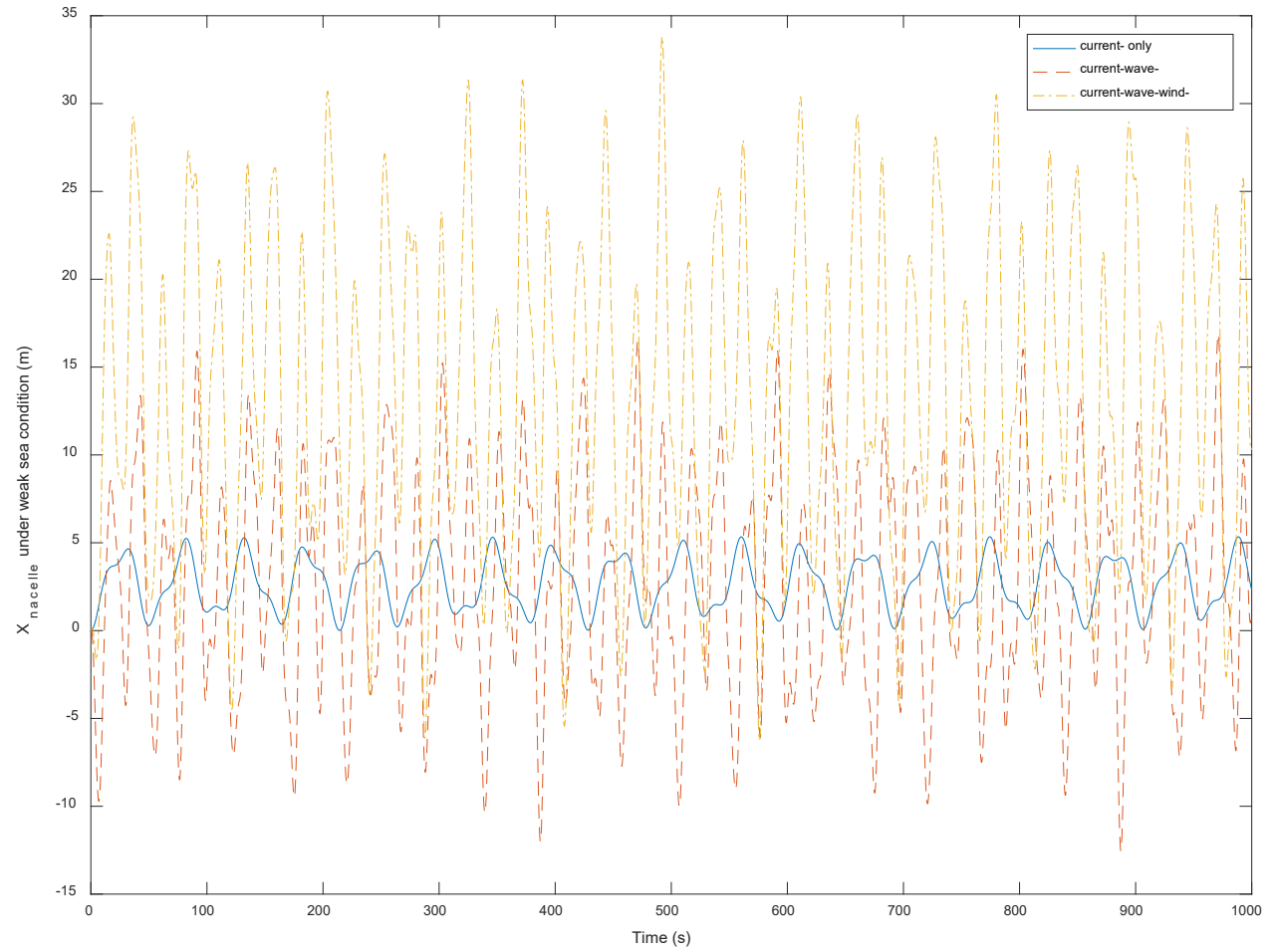



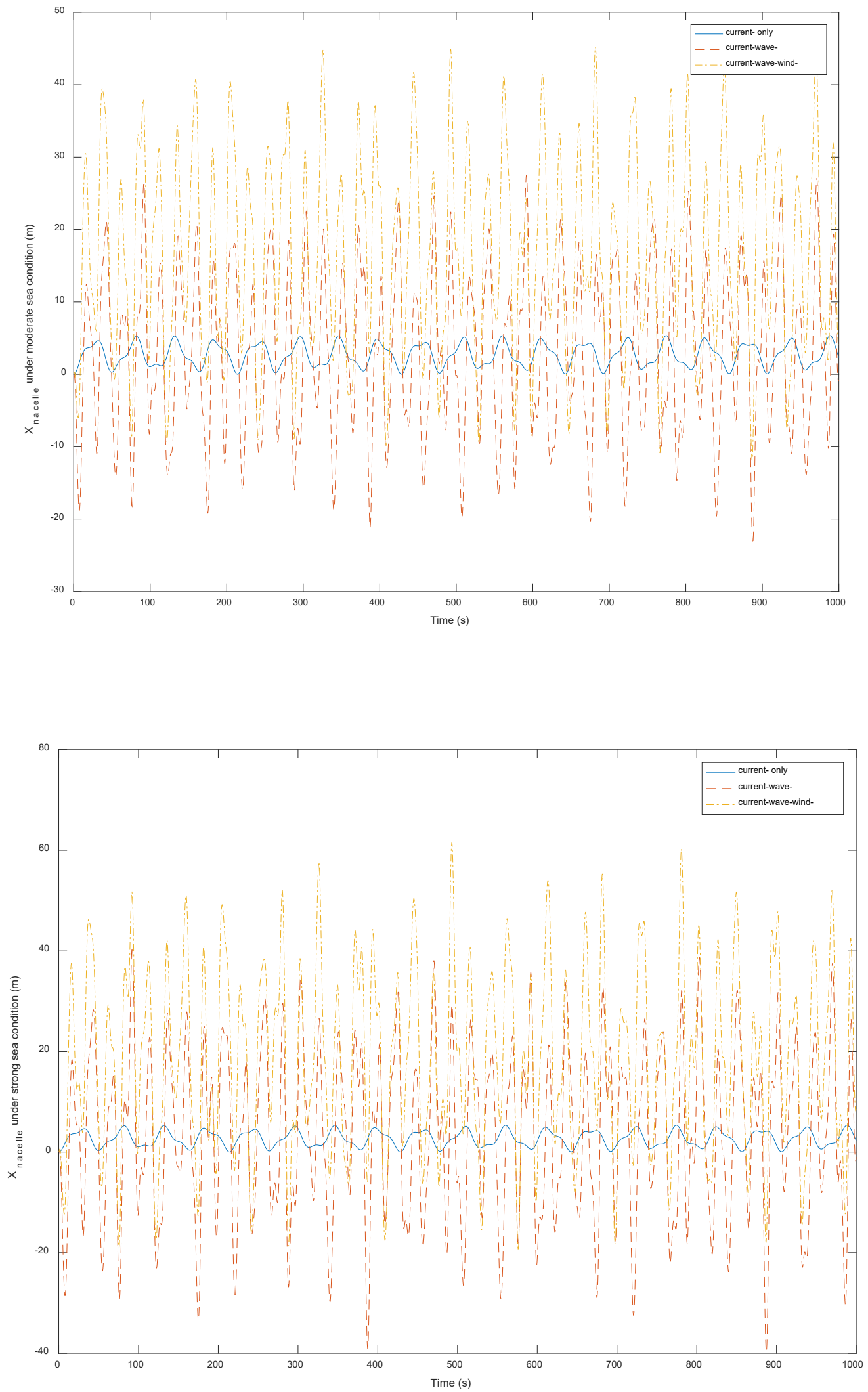

Figure 6 Time history of the nacelle's motion in the surge direction under (a) weak sea condition, (b) moderate sea condition, (c) strong sea condition 
Table 5 Nacelle performances in the surge direction

\begin{tabular}{|c|c|c|c|c|}
\hline Excitations & $\begin{array}{c}\text { Sea } \\
\text { condition }\end{array}$ & $\begin{array}{c}\text { Maximum } \\
\text { displacement(m) }\end{array}$ & $\begin{array}{c}\text { Mean } \\
\text { displacement(m) }\end{array}$ & $\begin{array}{c}\text { Standard } \\
\text { deviation }\end{array}$ \\
\hline Current only & & 5.35 & 2.67 & 1.49 \\
\hline \multirow{2}{*}{$\begin{array}{c}\text { Current and } \\
\text { wave }\end{array}$} & Weak & 16.83 & 2.66 & 6.22 \\
\cline { 2 - 5 } & Moderate & 27.4 & 2.89 & 10.94 \\
\cline { 2 - 5 } & Strong & 40.84 & 3.45 & 16.32 \\
\hline \multirow{2}{*}{$\begin{array}{c}\text { Current, wave } \\
\text { and wind }\end{array}$} & Weak & 33.69 & 13.25 & 8.93 \\
\cline { 2 - 5 } & Moderate & 45.19 & 16.7 & 13.2 \\
\cline { 2 - 5 } & Strong & 61.66 & 18.72 & 17.55 \\
\hline
\end{tabular}

\subsection{Effect of the dynamic interaction on the performance of the platform and} the drive-train system

In order to investigate the effect of the dynamic interaction between the drive-train system and the platform with tower structure, the wind turbine model is simulated by considering the drivetrain system as a point mass firstly and the drive-train system itself without the interaction, and then the interaction from the rotating drive-train system is considered. In this subsection, the wind, wave and current are assumed in the same direction. For the drive-train system under a fixed stator condition, the stator and the bearings are fixed and constrained in all directions. The performance of the CG's motion and the rotor's motion can be found directly from Eq.(5), while under the interaction condition, such performances should also take the motion of the nacelle into account. The displacement of the CG of the drive-train system and the rotor in the local coordinate system is compared to examine their dynamic performances, as shown in Figure 8. Under the fixed stator condition, the maximum displacement of the CG is $9.72 \times$ $10^{-6} \mathrm{~m}$ at $8.3 \mathrm{rpm}$ and $2.03 \times 10^{-5} \mathrm{~m}$ at $12 \mathrm{rpm}$, maximum displacement of rotor is $1.84 \times$ $10^{-5} \mathrm{~m}$ at $8.3 \mathrm{rpm}$ and $3.83 \times 10^{-5} \mathrm{~m}$ at $12 \mathrm{rpm}$. Under the interaction condition, the maximum displacement of the CG under the local coordinate system is $9.92 \times 10^{-6} \mathrm{~m}$ at $8.3 \mathrm{rpm}$ and 
$2.06 \times 10^{-5} \mathrm{~m}$ at $12 \mathrm{rpm}$, the maximum eccentricity of rotor and stator is $1.82 \times 10^{-5} \mathrm{~m}$ at $8.3 \mathrm{rpm}$ and $3.76 \times 10^{-5} \mathrm{~m}$ at $12 \mathrm{rpm}$. A percentage difference of the performance can be introduced to study the effect of the interaction on the dynamic response by using the formula: difference $\%=\frac{\mathrm{R}_{\text {int }}-\mathrm{R}_{\mathrm{pm}}}{\mathrm{R}_{\mathrm{pm}}} \times 100 \%$

where $R_{i}$ is the displacement response, the subscript int represents the model with interaction and $\mathrm{pm}$ denotes the model without the interaction (also used in Figures 10 to 13). The differences under two conditions are only about $2 \%$ in their performance. This means the effect of the interaction on the dynamics of the drive-train system itself is small and can be ignored in some cases. 

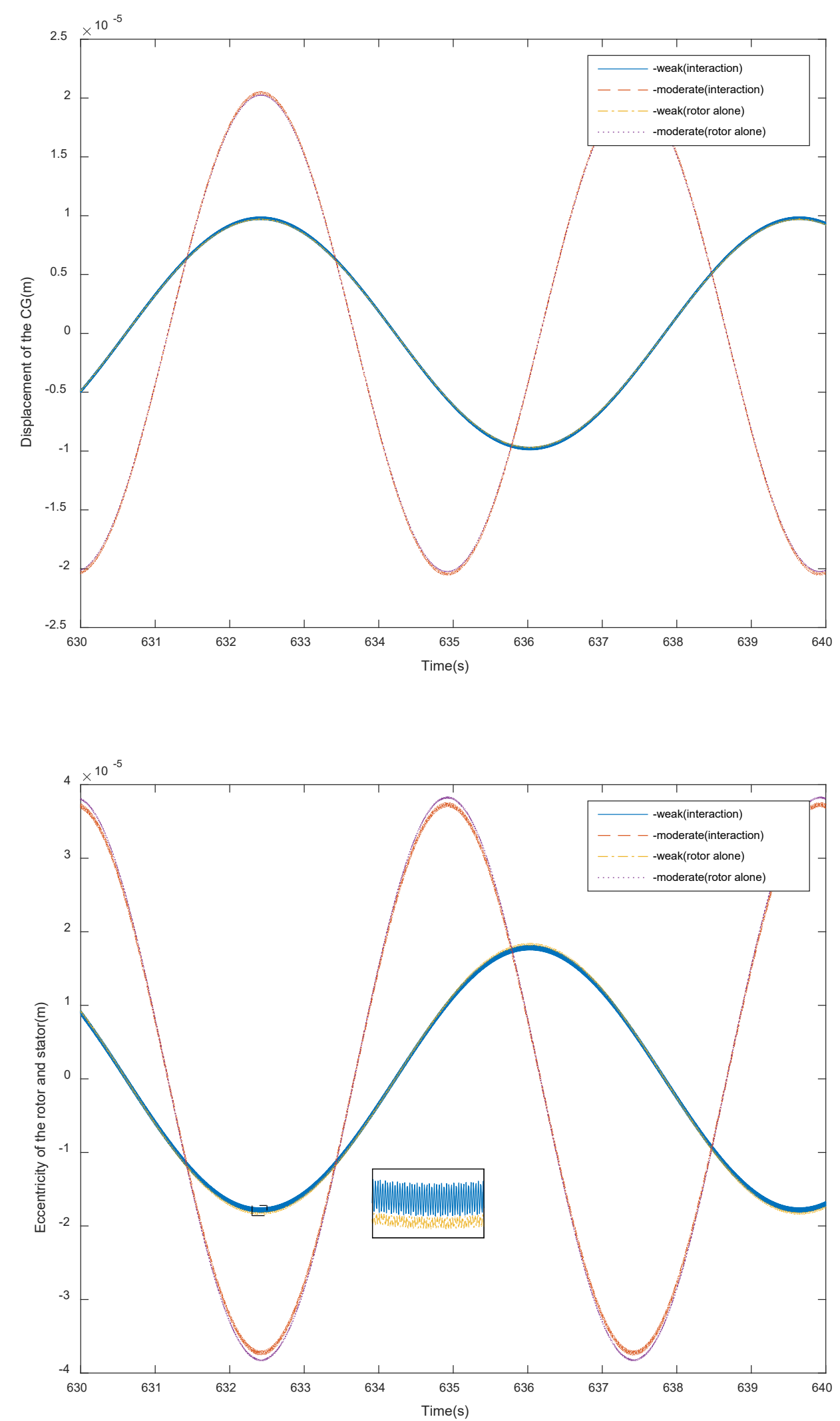

Figure 7 Time histories of the CG of the drive-train system and the rotor under the fixed stator and interaction conditions 
Figure 9 shows the motion of the nacelle in surge and sway directions under different sea conditions. The effect of the dynamic interaction on the spar supported platform is noticeable but not significant. In Figure 10, the differences in the frequency response for the nacelle's motion in the surge and sway directions are shown in the FFT spectrum figures. Additional frequency peak can be found in both surge and way directions due to the dynamic interaction and such frequency peak is associated with the rotating speed of the drive-train system. Figure 11 shows the performances of the nacelle's motion between the cut-in and cut-out wind speeds. The mean value of the nacelle's motion in the surge direction shows less than $1 \%$ difference. The maximum and standard deviation of the nacelle's motion in the surge direction is only up to $2.5 \%$ difference when considering the interaction. However, the maximum and mean value in the sway direction has increased significantly when the interaction is considered and the standard deviation of the motion in the sway direction remains within a small range. The reason for the large differences in the sway direction is that all excitations are assumed in the surge direction. The vibration in the sway direction is damped nearly to the steady state when the interaction is not induced. The dynamic interaction would generate additional excitation in the sway direction (perpendicular to the wind direction) which means that the effect of the interaction on the platform's motion is induced in the sway direction. As a result, the effect of the dynamic interaction is evident but not significant when the wave, wind and current are all in the same direction. However, different results will be expected when the wave and wind directions are changed, which will be discussed in the following section.

A notable increase can be found in the nacelle's motion in the sway direction when the wind speed is increased from 8 to $16 \mathrm{~m} / \mathrm{s}$. This change is attributable to the rotating speed of the drive-train system that corresponds to the wind speed. It is also noted that the increase of the nacelle's performance under strong sea condition due to the dynamic interaction, when the drive-train system stops rotating, still exists but the effect is reduced. This is because the 
eccentricity in the drive-train system is not only caused by self-rotating motion but also caused by its global translational motion. 

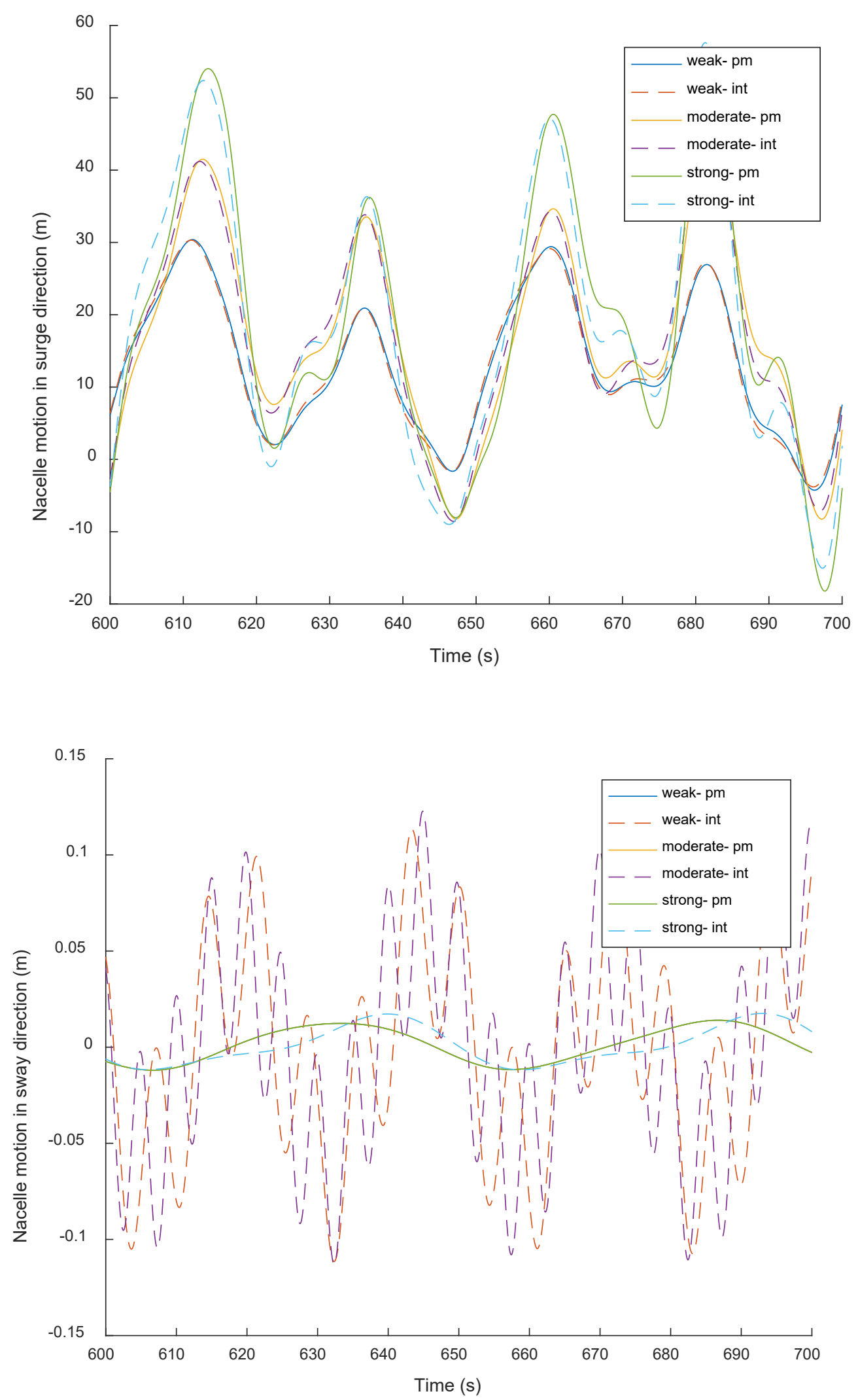

Figure 8 Time history of the platform motion in surge and sway directions 

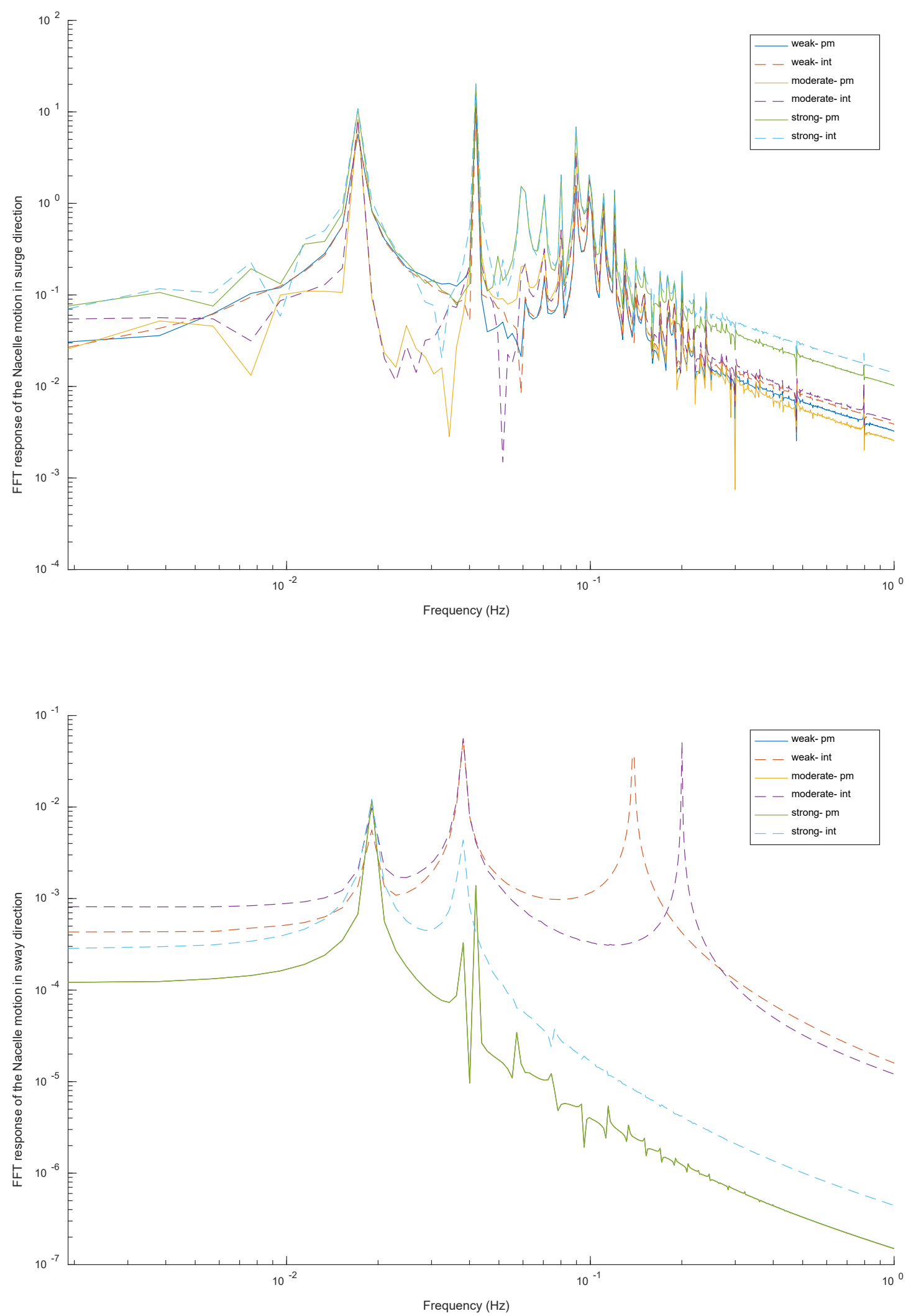

Figure 9 FFT of the nacelle's motion in the surge and sway directions 

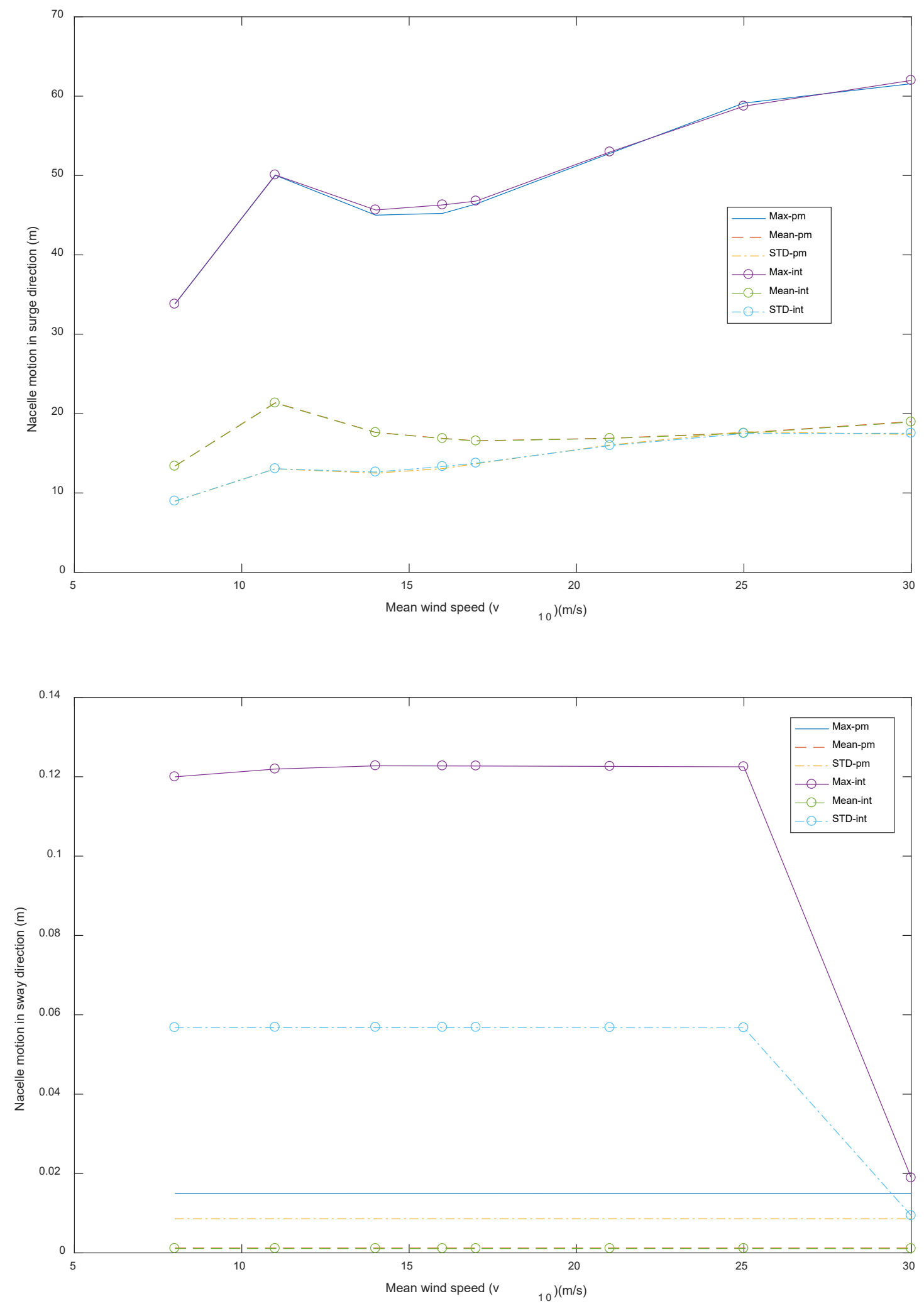

Figure 10 Performances of the platform motion in surge and sway directions 


\subsection{Effects of wind and current angle on the motion of the spar supported platform}

In order to form a complete 3D description of the deep sea environment, the directions of the wind and wave with reference to the sea current direction should also be considered. Significant changes are expected to happen when the wind direction is moving from the sea current direction to its opposite direction, while 180 degree could cover all possible cases and the performance in the other directions would have a mirrored trend about the surge axis. The performance of the nacelle's motion in surge and sway directions when the wind and current direction turns from 0 degree to 180 degree under different sea conditions are compared and shown in Figure 12. Firstly, the maximum displacement of the nacelle in the surge direction is reduced from 62 to $0 \mathrm{~m}$ when the wind direction is turning from the surge direction to its opposite direction meanwhile the mean displacement is reduced from 19 to $-13 \mathrm{~m}$. The maximum displacement of the nacelle in the sway direction is in the range of 0 to $58.5 \mathrm{~m}$. The maximum orbital motion of the nacelle can be found in the range of -49 to $62 \mathrm{~m}$ in the surge direction and -58.5 to $58.5 \mathrm{~m}$ in the sway direction for all wind conditions. This is caused by the current excitation with a fixed direction and the different resultant stiffnesses of the mooring system corresponding to the wind turbine's displacement. The differences of the dynamic response are also notable when the interaction is considered or not. The percentage differences of the mean and standard deviation values of the nacelle's motion are shown in Figure 13. For the nacelle's motion in the surge direction, a $-20 \%$ peak percentage change can be found at 105 degree for the mean value, which means a significant decrease of the mean value happens at $\theta_{w c}=105 \mathrm{deg}$ when considering the interaction. $\mathrm{A} \pm 20 \%$ peak percentage change at 75 degree and 105 degree for the standard deviation shows that the effect of the dynamic interaction would increase the vibration of the wind turbine in the surge direction when the wind direction is closer to sway direction. For the nacelle's motion in the sway 
direction, the percentage differences of the mean value and the standard deviation are within $10 \%$ for all three conditions. The percentage differences of the maximum values in both surge and sway directions are non-linear because the maximum value of the nacelle's motion is mainly dependant on the irregular wave excitation. By comparing the effects of the dynamic interaction under different sea conditions in both wind directions, it can be found that the absolute percentage difference of the mean value under the higher wind speed condition is always higher than that under low wind speed condition. On the contrary, the percentage difference of its standard deviation is lower, which means the effect of the interaction would be enhanced at the mean value but reduced at the standard deviation when sea condition is stronger (i.e., at higher wind speed). 


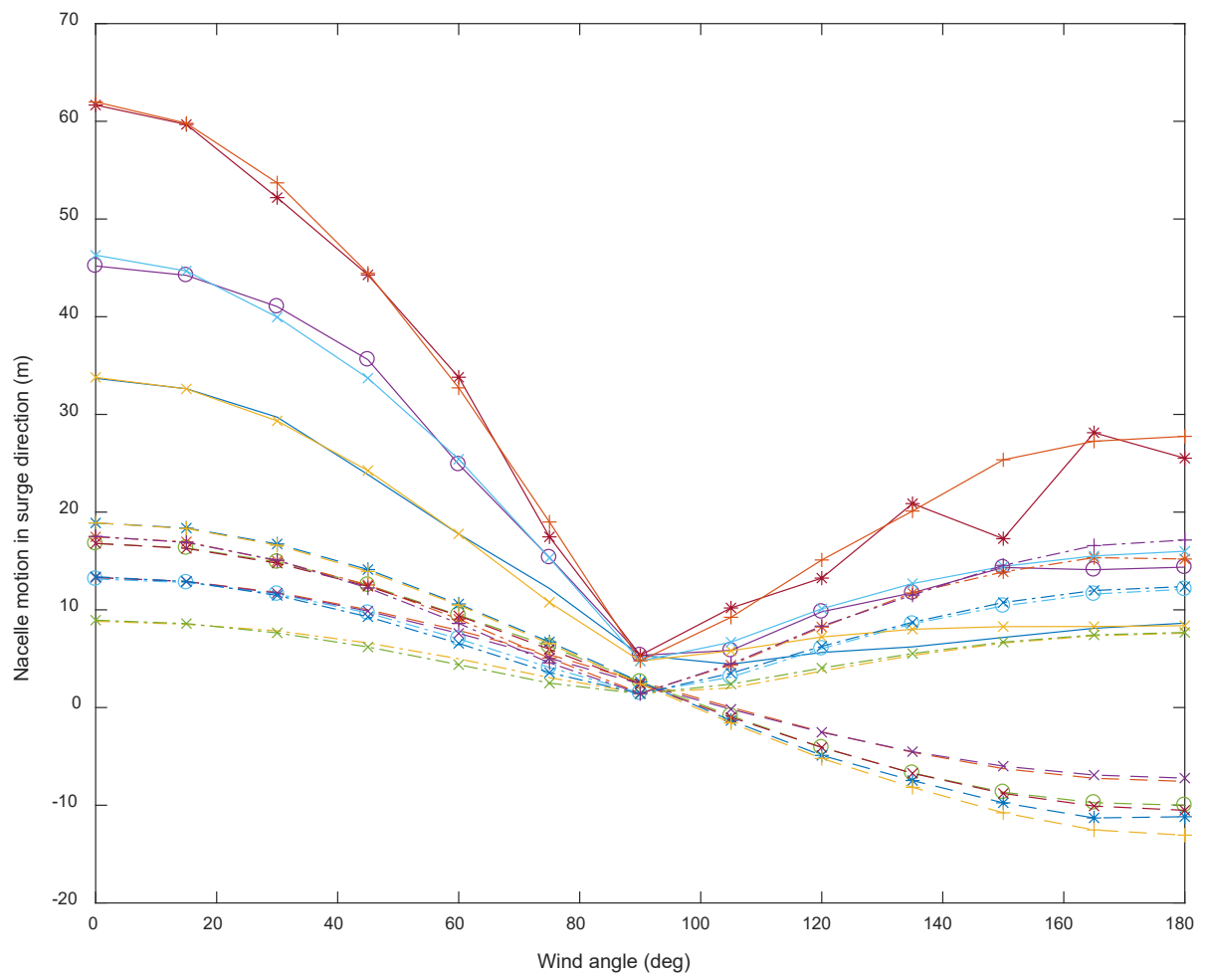

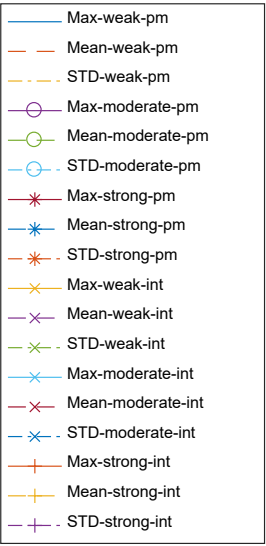

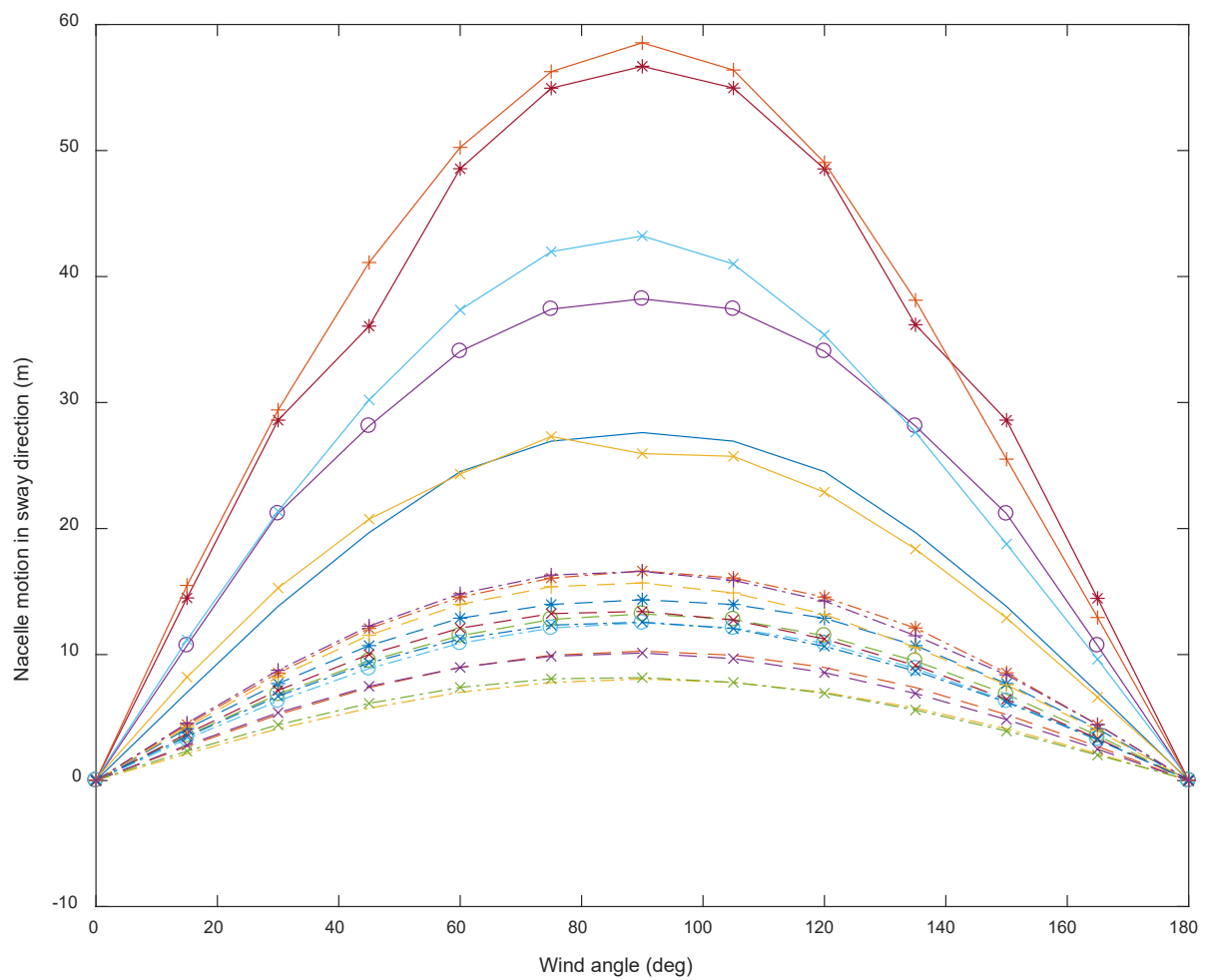

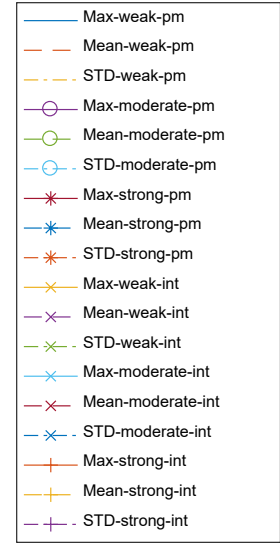

Figure 11 Nacelle's motion in surge and sway directions when changing the wind and current directions 

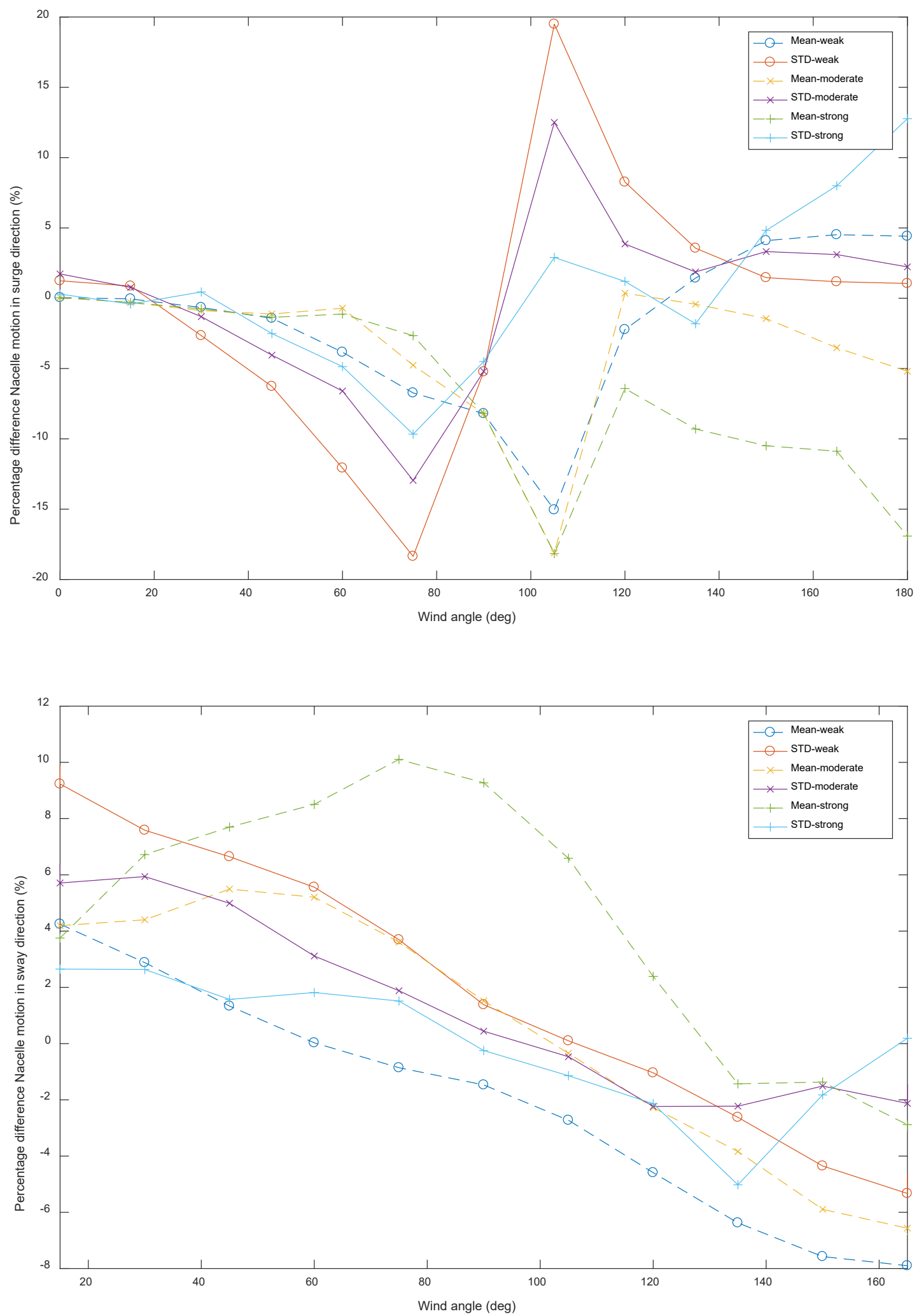

Figure 12 Percentage differences of the mean and standard deviation when changing the wind and current direction 


\section{Conclusion}

This paper studied the dynamic response of a spar-type floating direct-drive wind turbine caused by hydrodynamic and aerodynamic excitations. The hydrodynamic and aerodynamics excitations are generated from wind, sea current, wave and buoyancy. The comparison of the effects of the current, wave and wind excitations showed that the nacelle's mean displacement response is primarily wind induced and its standard deviation is primarily wave induced.

The dynamic interaction between the drive-train system and the platform with tower structure has been discussed. It was found that the interaction in the drive-train system is not only caused by self-rotating motion of the drive-train system but also caused by the global translational motion. However, the comparison of the response indicated that the effect of interaction between the drive-train system and the nacelle on the dynamic response of the drive-train itself can be ignored with a percentage difference of less than $3 \%$, whereas the effect on the spar support with tower structure is notable but not significant. The dynamic interaction can induce the nacelle motion's response in both surge and sway directions when the wave and wind are in the surge direction. The directions of the wind and wave with reference to the sea current direction were also considered to form a complete 3D description of the deep sea environment. The maximum orbital motion of the nacelle for different wind directions was found to be from -49 to $60 \mathrm{~m}$ in the surge direction and -58.5 to $58.5 \mathrm{~m}$ in the sway direction. By considering the interaction, the mean value and the standard deviation of the nacelle motion could lead to a $20 \%$ change in the surge direction and a $10 \%$ change in the sway direction. The effect of the interaction could be enhanced at the mean value but would be reduced at the standard deviation when the sea condition is stronger (the wind speed is higher). 


\section{Funding}

This research did not receive any specific grant from funding agencies in the public, commercial, or not-for-profit sectors.

\section{References}

[1] Dezvareh R, Bargi K, Mousavi SA. Control of wind/wave-induced vibrations of jackettype offshore wind turbines through tuned liquid column gas dampers. Structure and Infrastructure Engineering. 2016;12:312-26.

[2] Muliawan MJ, Karimirad M, Moan T. Dynamic response and power performance of a combined spar-type floating wind turbine and coaxial floating wave energy converter. Renewable Energy. 2013;50:47-57.

[3] Ramachandran GKV, Bredmose H, Sørensen JN, Jensen JJ. Fully coupled threedimensional dynamic response of a tension-leg platform floating wind turbine in waves and wind. Journal of Offshore Mechanics and Arctic Engineering. 2014;136:020901.

[4] Karimirad M, Moan T. Wave-and wind-induced dynamic response of a spar-type offshore wind turbine. Journal of Waterway, Port, Coastal, and Ocean Engineering. 2011;138:9-20. [5] Basu B, Zhang Z, Nielsen SR. Damping of edgewise vibration in wind turbine blades by means of circular liquid dampers. Wind Energy. 2016;19:213-26.

[6] Jonkman JM. Dynamics modeling and loads analysis of an offshore floating wind turbine: NERLTechnical Report, NREL/TP-500-41958, November 2007

[7] Musial W, Butterfield S, Boone A. Feasibility of floating platform systems for wind turbines. 23rd ASME Wind Energy Symposium, Reno, NV2004.

[8] Henderson AR, Zaaijer M, Bulder B, Pierik J, Huijsmans R, van Hees M et al. Floating windfarms for shallow offshore sites. The Fourteenth International Offshore and Polar Engineering Conference. Toulon, France: International Society of Offshore and Polar Engineers; 23-28 May 2004.

[9] Butterfield CP, Musial W, Jonkman J, Sclavounos P, Wayman L. Engineering challenges for floating offshore wind turbines. 2005 Copenhagen Offshore Wind Conference Copenhagen. Denmark, October 26-28, 2005.

[10] Pecher A, Foglia A, Kofoed JP. Comparison and sensitivity investigations of a CALM and SALM type mooring system for wave energy converters. Journal of Marine Science and Engineering. 2014;2:93-122.

[11] Guo Z, Wang L, Yuan F. Quasi-Static Analysis of the Multicomponent Mooring Line for Deeply Embedded Anchors. Journal of Offshore Mechanics and Arctic Engineering. 2016;138:011302.

[12] Colwell S, Basu B. Tuned liquid column dampers in offshore wind turbines for structural control. Engineering Structures. 2009;31:358-68.

[13] Zhang Z, Nielsen SR, Blaabjerg F, Zhou D. Dynamics and control of lateral tower vibrations in offshore wind turbines by means of active generator torque. Energies.

2014;7:7746-72.

[14] Adhikari S, Bhattacharya S. Dynamic analysis of wind turbine towers on flexible foundations. Shock and Vibration. 2012;19:37-56.

[15] Wei K, Myers AT, Arwade SR. Dynamic effects in the response of offshore wind turbines supported by jackets under wave loading. Engineering Structures. 2017;142:36-45. 
[16] Koukoura C, Brown C, Natarajan A, Vesth A. Cross-wind fatigue analysis of a full scale offshore wind turbine in the case of wind-wave misalignment. Engineering Structures. 2016;120:147-57.

[17] Karimirad M, Moan T. Extreme dynamic structural response analysis of catenary moored spar wind turbine in harsh environmental conditions. Journal of Offshore Mechanics and Arctic Engineering. 2011;133:041103.

[18] Sethuraman L, Xing Y, Gao Z, Venugopal V, Mueller M, Moan T. A 5MW direct-drive generator for floating spar-buoy wind turbine: Development and analysis of a fully coupled Mechanical model. Proceedings of the Institution of Mechanical Engineers, Part A: Journal of Power and Energy. 2014;228:718-41.

[19] Sethuraman L, Xing Y, Venugopal V, Gao Z, Mueller M, Moan T. A 5 MW direct-drive generator for floating spar-buoy wind turbine: Drive-train dynamics. Proceedings of the Institution of Mechanical Engineers, Part C: Journal of Mechanical Engineering Science. 2017;231:744-63.

[20] Ye K, Ji J. The effect of the rotor adjustment on the vibration behaviour of the drivetrain system for a $5 \mathrm{MW}$ direct-drive wind turbine. Proceedings of the Institution of Mechanical Engineers, Part C: Journal of Mechanical Engineering Science.

2017:0954406217729418.

[21] Sethuraman L, Venugopal V, Zavvos A, Mueller M. Structural integrity of a direct-drive generator for a floating wind turbine. Renewable Energy. 2014;63:597-616.

[22] Ragheb A, Ragheb M. Wind turbine gearbox technologies. Nuclear \& Renewable Energy Conference (INREC), 2010 1st International. Amman, Jordan21-24 March 2010. [23] Jonkman JM, Butterfield S, Musial W, Scott G. Definition of a 5-MW reference wind turbine for offshore system development. National Renewable Energy Laboratory Golden, CO, USA,Technical Report, NREL/TP-500-38060 February 2009.

[24] Jonkman JM. Definition of the floating system for phase IV of OC3: National Renewable Energy Laboratory Golden, CO, USA, Technical Report, NREL/TP-500-47535; May 2010.

[25] Poore R, Lettenmaier T. Alternative Design Study Report: WindPACT Advanced Wind Turbine Drive Train Designs Study; November 1, 2000--February 28, 2002. National Renewable Energy Laboratory (NREL), Golden, CO.Subcontractor report, NREL/SR-500331962003.

[26] Fingersh L, Hand M, Laxson A. Wind turbine design cost and scaling model. National Renewable Energy Laboratory (NREL), Golden, CO. Technical Report, NREL/TP-50040566 December 2006.

[27] Malcolm D, Hansen A. WindPACT turbine rotor design study. National Renewable Energy Laboratory, Golden, CO, Subcontract Report, NREL/SR-500-32495 Revised April 2006

[28] Murtagh P, Basu B, Broderick B. Along-wind response of a wind turbine tower with blade coupling subjected to rotationally sampled wind loading. Engineering Structures. 2005;27:1209-19.

[29] Chandrasekaran S, Jain A. Triangular configuration tension leg platform behaviour under random sea wave loads. Ocean Engineering. 2002;29:1895-928.

[30] Massel SR. Ocean surface waves: their physics and prediction: Vol. 36. World scientific; 2013.

[31] Hasselmann K, Barnett T, Bouws E, Carlson H, Cartwright D, Enke K et al. Measurements of wind-wave growth and swell decay during the Joint North Sea Wave Project (JONSWAP). Ergänzungsheft 8-12. 1973. 
[32] Johannessen K, Meling TS, Hayer S. Joint distribution for wind and waves in the northern north sea. The Eleventh International Offshore and Polar Engineering Conference. Stavanger, Norway: International Society of Offshore and Polar Engineers; 17-22 June 2001. [33] Li HJ, Hu S-LJ, Jakubiak C. H 2 active vibration control for offshore platform subjected to wave loading. Journal of Sound and Vibration. 2003;263:709-24.

[34] Ditlevsen O. Stochastic model for joint wave and wind loads on offshore structures. Structural Safety. 2002;24:139-63. 